\title{
Shakedown analysis of elastic-plastic structures considering the effect of temperature on yield strength: theory, method and applications
}

\author{
Heng Peng ${ }^{1}$, Yinghua Liu ${ }^{1, *}$, Haofeng Chen $^{2}$ \\ ${ }^{1}$ Department of Engineering Mechanics, AML, Tsinghua University, Beijing 100084, People’s Republic of China \\ ${ }^{2}$ Department of Mechanical and Aerospace Engineering, University of Strathclyde, Glasgow G1 1XJ, UK \\ *Corresponding author: yhliu@mail.tsinghua.edu.cn
}

\section{ABSTRACT}

According to the extended Melan's static theorem, theoretical and numerical aspects of the stress compensation method (SCM) are presented to perform shakedown analysis of elastic-plastic structures considering the effect of temperature on yield strength. Instead of constructing a mathematical programming formulation, this developed method consists of the two-level iterative scheme. The inner loop constructs the statically admissible self-equilibrating stress field, while the outer loop evaluates a sequence of decreasing load factors to approach to the shakedown limit multiplier. The yield strength considering temperature effect is updated based on the current temperature at each outer iteration, and the yield conditions are checked at all Gauss points. The numerical procedure is well incorporated into ABAQUS finite element code and used for calculating the shakedown limits of structures considering yield strengths as different functions of temperature under complex thermomechanical loading system. The method is validated by some plane stress and axisymmetric numerical examples with theoretical and numerical solutions, and subsequently applied to solve the practical shakedown problem of a pipe with oblique nozzle. The results demonstrate that the developed method is stable, accurate and efficient, and can effectively evaluate the shakedown limit of an elastic-plastic structure where the yield strength of material varies with temperature.

Keywords: shakedown analysis; effect of temperature; yield strength; stress compensation method; thermomechanical loading

\section{Introduction}

In modern engineering design standards and codes, such as EN 13445-3 and ASME VIII-2, the plastic failure mechanisms of structures are addressed with the objective to evaluate the load-carrying capability of structures 
made of ductile materials. More pressure vessels and pipes, equipment of nuclear reactors and economic steel structures under variable thermal and mechanical loads are designed with checks against ratcheting (or incremental plastic collapse) and alternating plasticity (or local low-cycle fatigue) (Staat and Heitzer, 2003). Instead of limiting the behavior of structural elements or components to the elastic range, these design codes allow some limited plastic deformation provided the structures shake down to the elastic behavior after some load cycles. Therefore, for these structures under repeated variable loads, shakedown limit is a significant design parameter to engineers. The shakedown analysis just aims to determine the allowable load range, within which the structure will not failure due to the ratcheting or the alternating plasticity (König, 1987).

Shakedown problems have attracted extensive attentions of academic researchers and engineers in fields of mathematics, material, mechanics, and structural engineering (Maier, 2001; Stein et al., 1993; Ponter and Carter, 1997a, b; Zarka, 1980; Ponter and Chen, 2001; Chinh, 2005; Liu et al., 2005; Polizzotto, 2008; Simon and Weichert, 2011; Zouain et al., 2002; Casciaro and Garcea, 2002; Chen et al., 2011; Nguyen-Xuan et al., 2012; Spiliopoulos and Panagiotou, 2014; Peigney, 2014; Ponter, 2016; Do and Nguyen-Xuan, 2017; Cho and Chen, 2018). However, it is still difficult to implement shakedown analysis well for practical complex engineering structures in design process. One difficulty remains in how the shakedown theorem meets the actual engineering conditions (Weichert and Ponter, 2014). The classical Melan-Koiter shakedown theorems (Melan, 1938; Koiter, 1960) rest on the assumption of temperature-independent material property. However, many structural elements and components in nuclear and power producing plant usually work in high and variable temperature environment, and thus the temperature has large effects on some material parameters, especially on the yield strength. The shakedown analysis is complicated when temperature effect on material property is taken into consideration. Another difficulty is the computing tool for solving large-scale complex shakedown problems. One approach for determining the shakedown limit is to simulate some cyclic responses of elastoplastic structures under some cyclic loading processes with different load levels via the incremental finite element (FE) analysis (König, 1987). However, these step-by-step procedures cause a high calculating cost for actual engineering structures, since the steady cyclic state usually achieves after many load cycles. The direct method (Maier, 2001; Weichert and Ponter, 2014), as a better alternative, can be efficiently used for straightforward calculation of the shakedown limit just with knowledge of the bounding box of cyclic loads rather than the detailed loading history.

Many researchers have investigated the shakedown analysis considering the temperature-dependent material property (Prager, 1956; König, 1969; Vu and Staat, 2007; Peigney, 2014). The classical Melan's shakedown 
theorem was extended to include the variation of the yield strength with respect to temperature (Prager, 1956; Borino, 2000), where the constant residual stress field is required to be found. Although the static shakedown theorem considering the temperature-dependent yield strength was established, allowing the elastic moduli to vary with temperature has been recognized to be a difficult and challenging problem where the proof of Melan's theorem is violated (Halphen, 2005; Hasbroucq et al., 2010). Recently, Hasbroucq et al. (2012) presented a static shakedown theorem with temperature-dependent elastic moduli, which enounces that the constant residual stress field should be replaced by a constant plastic strain field. The residual stress field changes during the cycle due to the varying elastic moduli. The proof of this shakedown theorem and some theoretical results for a simple bar structure were given in Peigney (2014). In general, although some basic properties of engineering materials are all temperature-dependent, the temperature has more significant effects on the yield strength than on other material parameters, such as thermal expansion coefficient, Young's modulus and Poisson's ratio. For an ordinary high-temperature steel, there exists about $35 \%$ reduction of yield strength when its temperature increases from $20^{\circ} \mathrm{C}$ to $350^{\circ} \mathrm{C}$. Therefore, it is very significant to present some theorems and efficient direct methods to solve the practical complex shakedown problem considering the temperature effect on yield strength of material.

Since Prager (1956) extended the classical static shakedown theorem of Melan to cover thermal loads and materials with the consideration of temperature effect on yield strength, some relevant studies have been reported (Naghdi, 1960; Bree, 1967; Gokhfeld and Charniavsky, 1980; Borino, 2000; Yan and Hung, 2001; Heitzer, 2004; Vu and Staat, 2007). Naghdi (1960) pointed out that, for the static approach to shakedown problem, the yield surface can be described by some parameters depending on the actual temperature of a material point, but the yield surface must be convex and the normality law should be applied. The corresponding extension of the classical Koiter's kinematic shakedown theorem was achieved by König to consider the temperature-dependent yield stress, and some simple examples were given in his treatise (König, 1987). For the aspect of application, Bree (1967) proposed a classical shakedown-ratcheting (Bree) diagram to investigate the elastoplastic behavior of a tube under cyclic thermal load and constant pressure, and the shakedown boundary was discussed with the consideration of mean temperature effect on yield strength. A systematic presentation of theorems and methods about the limit-state of structures under cyclic thermal loading were given by Gokhfeld and Cherniavsky in their monograph (Gokhfeld and Charniavsky, 1980).

It should be noted that these extensions mentioned above just consider the ideal plastic material whose yield function is restrict to be convex in stress $\sigma$ space at every temperature $\theta$. After that, Borino (2000) stated 
that the calculated shakedown limits based on the Prager's and König's extended theorems cannot keep duality of the upper and lower bounds if the yield stress has a nonlinear relationship with the temperature. To overcome these difficulties, he established a consistent shakedown theorem under the framework of thermodynamics considering the yield function convex in $\sigma-\theta$ space. Then, using this modified theorem, Yan and Hung (2001) presented the nonlinear kinematic method, by which the upper shakedown analysis considering the effect of temperature on yield strength was realized using the König's extended kinematic theorem. Furthermore, Heitzer (2004) described a general static method for temperature-dependent shakedown calculation of structures using nonlinear optimization, but this method was inapplicable to the problem with constant loads. By applying some restrictions to the thermal loading condition, Vu and Staat (2007) established a linearized shakedown theorem where the yield stress was linearized and the shakedown analysis was formulated as a convex optimization problem.

Although these shakedown analyses above considered the evaluation of the shakedown limit of elasticplastic structure with temperature-dependent yield strength, using the mathematic programming methods, they appear to address academic research and just deal with some simple structures. When a real complex engineering component is considered, these shakedown analyses are translated into the tremendous optimization problems which are hard to solve. Besides the mathematic programming methods, there are still some other direct methods, such as the elastic compensation method (ECM) (Ponter and Carter, 1997a, b; Ponter and Engelhardt, 2000), the linear matching method (LMM) (Chen and Ponter, 2001; Chen, 2010; Barbera and Chen, 2015; Barbera et al., 2017) and the stress compensation method (SCM) (Peng et al., 2018), which go around the difficulty of the optimization problem and are more suitable for practical engineering applications. The LMM simulates the plastic behavior via a series of full elastic solutions with variable moduli in time and space to evaluate shakedown limit. With no need to generate the programming formulation, the SCM just performs a sequence of iterative calculations, where the global stiffness matrix is required to be assembled and decomposed only once. However, this work is restricted to the classical Melan's theorem and assumes the temperature-independent material property, which could be violated when the structures undergo high and variable temperature.

This article mainly aims to develop an effective method to carry out the shakedown calculation of elasticplastic structures with temperature-dependent yield strength under complex thermomechanical loading system. The theoretical foundations, numerical procedure and practical applications of the SCM are elaborated in detail to consider the linear and nonlinear temperature dependence of yield strength of material. The article is outlined as follows. Sect. 2 presents the extended static theorem of shakedown for elastic-plastic material considering 
117 temperature effect on yield strength. Sect. 3 and Sect. 4 present the theoretical and numerical aspects of the 118 developed method for complex thermomechanical loading system, respectively. Then some analytical and 119 numerical examples are considered for the validation and application of the developed method to engineering 120 structures in Sect. 5. Finally, Sect. 6 provides some conclusions.

\section{2. Extended static shakedown theorem}

\subsection{Loading history and loading domain}

A given structure (or solid body) $V$ is composed of material points, whose coordinate vectors can be denoted

124 by $\mathbf{x} \in V$. The loading history $\mathbf{P}(\mathbf{x}, t)$ of the structure is defined as the superposition of loading sets $\mathbf{P}_{i}(\mathbf{x}, t)$, $125 i=(1, \cdots, N)$. Each loading set $\mathbf{P}_{i}(\mathbf{x}, t)$ is decided by the time-independent load $\overline{\mathbf{P}}_{i}(\mathbf{x})$ and the time126 dependent factor $\mu_{i}(t)$, that is

$$
\mathbf{P}(\mathbf{x}, t)=\sum_{i=1}^{N} \mathbf{P}_{i}(\mathbf{x}, t)=\sum_{i=1}^{N} \mu_{i}(t) \overline{\mathbf{P}}_{i}(\mathbf{x})
$$

128 Considering that the time-dependent factor $\mu_{i}(t)$ varies arbitrarily within a given range of itself:

$$
\mu_{i}^{-} \leq \mu_{i}(t) \leq \mu_{i}^{+}
$$

where $\mu_{i}^{-}$and $\mu_{i}^{+}$are the marginal values of the factor $\mu_{i}(t)$, these $N$ loads form a $N$-dimensional loading 131 domain $\mathbf{\Omega}$, i.e., a polyhedron defined by $m=2^{N}$ vertices in load parameter space. If we assume $\mathbf{P}_{i}^{V}(\mathbf{x})$ $i=(1, \cdots, m)$ is the vector of load vertex $i$, the loading history $\mathbf{P}(\mathbf{x}, t)$ can be represented as another form:

$$
\mathbf{P}(\mathbf{x}, t)=\sum_{i=1}^{m} \gamma_{i}(t) \mathbf{P}_{i}^{V}(\mathbf{x})
$$

134 where theses coefficients $\gamma_{i}(t), i=(1, \cdots, m)$ should satisfy the following conditions:

$$
\gamma_{i}(t) \geq 0, i=(1, \cdots, m) \text { and } \sum_{i=1}^{m} \gamma_{i}(t) \leq 1
$$

136 As displayed in Fig. 1, a four-vertex loading domain in two-dimensional space is taken as an example. 

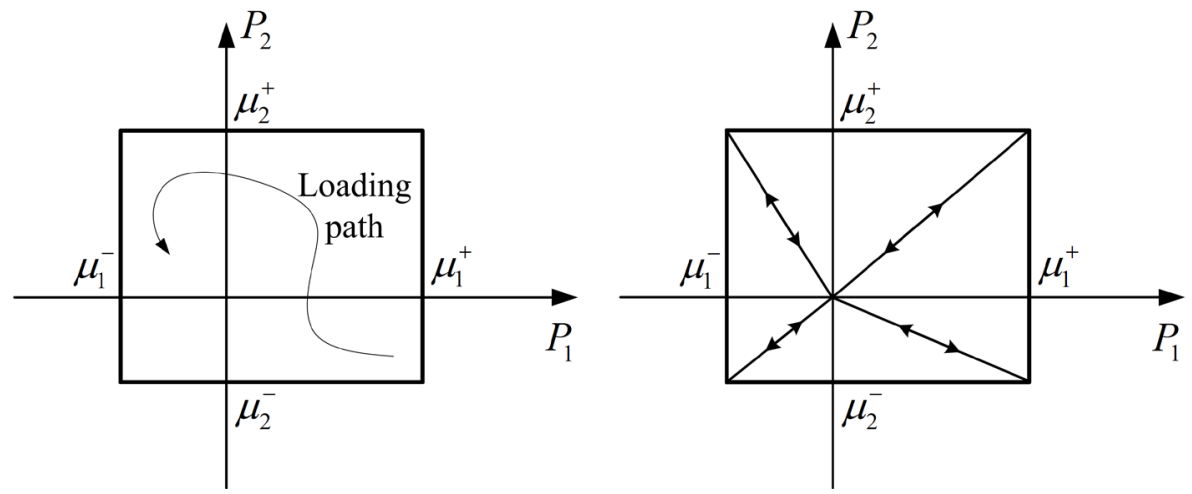

Fig. 1. Loading domain $\boldsymbol{\Omega}$ and loading path.

Now we assume a solid body is subject to both mechanical and thermal loads as well as temperature variation varying in a quasi-static process. The mechanical and thermal loads depend on a group of time-dependent load parameters $\mathbf{P}(\mathbf{x}, t)=\left[\mathbf{P}^{M}(\mathbf{x}, t), \mathbf{P}^{\theta}(\mathbf{x}, t)\right]$, where $\mathbf{P}^{M}(\mathbf{x}, t)$ is mechanical load set and $\mathbf{P}^{\theta}(\mathbf{x}, t)$ is thermal load set. $\mathbf{P}^{M}(\mathbf{x}, t)$ and $\mathbf{P}^{\theta}(\mathbf{x}, t)$ can vary within the given domains $\mathbf{\Omega}^{M}$ and $\mathbf{\Omega}^{\theta}$, respectively. In general, we assume that the given domains $\mathbf{\Omega}^{M}$ and $\boldsymbol{\Omega}^{\theta}$ are convex polyhedrons defined by $m^{M}$ and $m^{\theta}$ vertices, respectively, in the load parameter space. Then $\mathbf{P}(\mathbf{x}, t)$ will vary arbitrarily within the domain $\boldsymbol{\Omega}$, which is a convex hyper polyhedron containing $m=m^{M} \times m^{\theta}$ vertices. The time-dependent load parameters $\mathbf{P}(\mathbf{x}, t)$ can also be represented as Eqs. (3) and (4).

Assuming that the body is fully elastic, the fictitious elastic stress $\boldsymbol{\sigma}^{E}(\mathbf{x}, t)$ is unique to the load $\mathbf{P}(\mathbf{x}, t)$. Thus, the fictitious elastic stress domain $\mathbf{E}$ is also a hyper polyhedron containing $m$ vertices and can be denoted as

$$
\boldsymbol{\sigma}^{E}(\mathbf{x}, t)=\sum_{i=1}^{m} \gamma_{i}(t) \boldsymbol{\sigma}_{i}^{V}(\mathbf{x})
$$

where $\boldsymbol{\sigma}_{i}^{V}(\mathbf{x})=\left[\boldsymbol{\sigma}_{i}^{V M}(\mathbf{x}), \boldsymbol{\sigma}_{i}^{V \theta}(\mathbf{x})\right]$ denotes the thermoelastic stress of the body under the load sets $\mathbf{P}_{i}^{V}(\mathbf{x})=\left[\mathbf{P}_{i}^{V M}(\mathbf{x}), \mathbf{P}_{i}^{V \theta}(\mathbf{x})\right]$ and the temperature field $\theta_{i}^{V}(\mathbf{x})$. The temperature field history (or domain) $\theta(\mathbf{x}, t)$ can be represented as

$$
\theta(\mathbf{x}, t)=\sum_{i=1}^{m} \gamma_{i}(t) \theta_{i}^{V}(\mathbf{x})
$$

The detailed elastoplastic response of a structure under any loading history $\mathbf{P}(\mathbf{x}, t)$ varying within the domain $\boldsymbol{\Omega}$ can be obtained via the incremental FE analysis considering the real constitutive equations. However, the main concerns of our interest are whether the structure shakes down under the considered loading 
condition. As a better alternative, the shakedown theorem provides an effective criterion to estimate whether the shakedown occurs, without the knowledge of the complete stress or strain histories (König, 1987). The following section will present the static theorem of shakedown with temperature-dependent yield strength to cope with the considered problem of this article.

\subsection{Extended static theorem of shakedown with temperature-dependent yield strength}

For an elastic-plastic body, plastic strain will occur if its equivalent stress reaches the yield strength $\sigma_{y}(\theta)$. The actual stress $\boldsymbol{\sigma}(\mathbf{x}, t)$ can be divided into fictitious elastic stress $\boldsymbol{\sigma}^{E}(\mathbf{x}, t)$ and residual stress $\boldsymbol{\rho}(\mathbf{x})$. The extended Melan's theorem of shakedown for materials considering the temperature effect on yield strength states as follows : a structural body shakes down to the variable repeated loading, if a constant residual stress field $\boldsymbol{\rho}(\mathbf{x})$ and a load multiplier $\lambda$ is found, so that, for arbitrary temperature variations and loads within the specified limit domains, the following relations hold:

$$
\begin{gathered}
\boldsymbol{\sigma}(\mathbf{x}, t)=\lambda \boldsymbol{\sigma}^{E}(\mathbf{x}, t)+\boldsymbol{\rho}(\mathbf{x})=\lambda\left[\lambda_{M} \boldsymbol{\sigma}^{E M}(\mathbf{x}, t)+\lambda_{\theta} \boldsymbol{\sigma}^{E \theta}(\mathbf{x}, t)\right]+\boldsymbol{\rho}(\mathbf{x}) \\
f\left(\boldsymbol{\sigma}(\mathbf{x}, t), \sigma_{y}(\theta)\right)=\bar{\sigma}(\boldsymbol{\sigma}(\mathbf{x}, t))-\sigma_{y}\left(\lambda \lambda_{\theta} \theta(\mathbf{x}, t)\right) \leq 0 \quad \forall \mathbf{x} \in V, \quad \forall t
\end{gathered}
$$

where $\lambda_{M}$ and $\lambda_{\theta}$ are the factors of mechanical stress $\boldsymbol{\sigma}^{E M}(\mathbf{x}, t)$ and thermal stress $\boldsymbol{\sigma}^{E \theta}(\mathbf{x}, t)$, respectively; $\bar{\sigma}$ denotes equivalent stress; $f(\cdot)$ denotes the yield function which is required to be convex in $\sigma-\theta$ space; and $\sigma_{y}(\theta)$ denotes the yield strength depending on the current temperature $\theta$. The stress field $\boldsymbol{\rho}(\mathbf{x})$ satisfies self-equilibrating condition in the body $V$ and force boundary condition on the surface $S_{t}$, i.e.

$$
\begin{cases}\nabla \cdot \boldsymbol{\rho}(\mathbf{x})=\mathbf{0} & \text { in } V \\ \boldsymbol{\rho}(\mathbf{x}) \cdot \mathbf{n}=\mathbf{0} & \text { on } S_{t}\end{cases}
$$

where $\nabla \cdot$ denotes the divergence operator; and $\mathbf{n}$ denotes an outward normal of the surface $S_{t}$.

Fig. 2 presents a geometric illustration of static theorem of shakedown considering the temperature effect on yield strength. The key idea is to place the loading domain $\boldsymbol{\Omega}$ into the geometric space formed by yield condition for all loads and temperatures. The loading domain can be enlarged or shrunk by multiplying a factor $\lambda$. The maximum allowable value of the factor $\lambda$ is shakedown multiplier. It is worth emphasizing that, both fictitious elastic stress domain and yield condition consider the effect of temperature variation, thus the domain must be contained in the geometric space for all temperatures. 


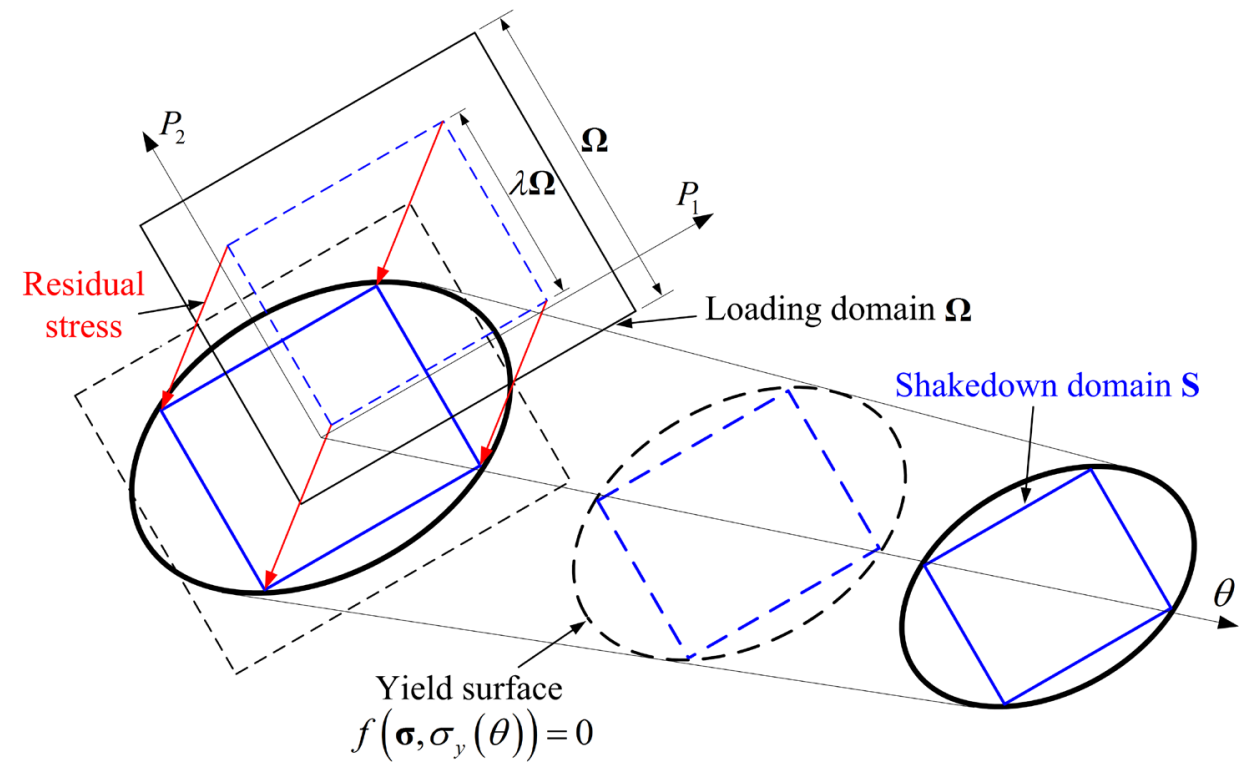

Fig. 2. Geometric illustration of static shakedown theorem considering the temperature effect on yield strength.

According to some recent studies (Borino, 2000; Yan and Hung, 2001; Heitzer, 2004; Vu and Staat, 2007) on the shakedown theorems for material considering the temperature effect on yield strength, theoretically, the yield function $f(\cdot)$ is required to be convex in $\sigma-\theta$ space. In general, this is not difficult in most cases. For the convexity of von Mises yield function, this requirement can be easily satisfied if yield stress $\sigma_{y}(\theta)$ is restrict to be concave or linearized with respect to temperature $\theta$. In fact, lots of metal alloys meet this requirement of the concavity of $\sigma_{y}(\theta)$ for a wide temperature range. Besides, even if the function between yield stress and temperature is convex, the piecewise linearization of yield stress function versus temperature turns out to be a particularly useful approach (Vu and Staat, 2007). In this work, the piecewise linearization of the yield stress function versus temperature can be easily carried out by partitioning the temperature range into some sub-ranges, just resulting in the increase of the number of vertices $m^{\theta}$.

\section{Theoretical aspect of the SCM with temperature-dependent yield stress}

We suppose that an elastic-perfectly plastic material obeys the von Mises yield criterion with associated flow rule. To investigate the temperature effect on shakedown problem, the yield strength of material is considered temperature-dependent.

The strain rate $\dot{\boldsymbol{\varepsilon}}(t)$ can be divided into five parts:

$$
\dot{\boldsymbol{\varepsilon}}(t)=\lambda\left[\lambda_{M} \dot{\boldsymbol{\varepsilon}}^{E M}(t)+\lambda_{\theta} \dot{\boldsymbol{\varepsilon}}^{E \theta}(t)+\lambda_{\theta} \dot{\boldsymbol{\varepsilon}}_{\theta}(t)\right]+\dot{\boldsymbol{\varepsilon}}_{r}^{e}(t)+\dot{\boldsymbol{\varepsilon}}^{p}(t)
$$


where $\dot{\boldsymbol{\varepsilon}}^{E M}(t)$ and $\dot{\boldsymbol{\varepsilon}}^{E \theta}(t)$ are the strain rates of a body under the elastic mechanical stress rate $\dot{\boldsymbol{\sigma}}^{E M}(t)$ and thermal stress rate $\dot{\boldsymbol{\sigma}}^{E \theta}(t)$, respectively; $\dot{\boldsymbol{\varepsilon}}_{\theta}(t)=\alpha \dot{\theta}(t) \mathbf{I}$ is the strain rate due to thermal expansion; $\dot{\boldsymbol{\varepsilon}}_{r}^{e}(t)$ is the residual elastic strain rate which is induced by the the residual stress; and $\dot{\boldsymbol{\varepsilon}}^{p}(t)$ denotes the plastic strain rate.

According to the constitutive law, the stress and strain have the following relation expressions:

$$
\dot{\boldsymbol{\sigma}}^{E}(t)=\mathbf{D} \cdot \dot{\boldsymbol{\varepsilon}}^{E}(t)
$$

$$
\dot{\boldsymbol{\rho}}(t)=\mathbf{D} \cdot \dot{\boldsymbol{\varepsilon}}_{r}^{e}(t)
$$

where D denotes the elastic stiffness matrix.

For the FE analysis, the strain rates $\dot{\boldsymbol{\varepsilon}}(t)$ of an element are related to the nodal displacement rates $\dot{\mathbf{u}}(t)$.

$$
\dot{\boldsymbol{\varepsilon}}(t)=\mathbf{B} \cdot \dot{\mathbf{u}}(t)
$$

where $\mathbf{B}$ denotes the strain-displacement matrix.

We substitute Eq. (10) into (12), then the residual stress rate is represented as

where $\delta \dot{\boldsymbol{\varepsilon}}(t)$ denotes the virtual strain rate and the superscript letter T denotes transpose operation, we get

$$
\dot{\boldsymbol{\rho}}(t)=\mathbf{D} \cdot\left\{\dot{\boldsymbol{\varepsilon}}(t)-\lambda\left[\lambda_{M} \dot{\boldsymbol{\varepsilon}}^{E M}(t)+\lambda_{\theta} \dot{\boldsymbol{\varepsilon}}^{E \theta}(t)+\lambda_{\theta} \alpha \dot{\theta}(t) \mathbf{I}\right]-\dot{\boldsymbol{\varepsilon}}^{p}(t)\right\}
$$

Substituting Eqs. (13) and (14) into the virtual work equation:

$$
\int_{V} \delta \dot{\boldsymbol{\varepsilon}}^{\mathrm{T}}(t) \cdot \dot{\boldsymbol{\rho}}(t) d V=0
$$

$$
\delta \dot{\mathbf{u}}^{\mathrm{T}}(t) \cdot\left\{\int_{V} \mathbf{B}^{\mathrm{T}} \cdot \mathbf{D} \cdot\left[\mathbf{B} \cdot \dot{\mathbf{u}}(t)-\lambda\left[\dot{\boldsymbol{\varepsilon}}^{E}(t)+\alpha \dot{\theta}(t) \mathbf{I}\right]-\dot{\boldsymbol{\varepsilon}}^{p}(t)\right] d V\right\}=0
$$

where $\mathbf{K}$ denotes the structural global stiffness matrix. We replace $\mathbf{D} \cdot \dot{\boldsymbol{\varepsilon}}^{p}(t)$ with the compensation stress $\boldsymbol{\sigma}^{C}(t)$ and put Eqs. (11) and (13) into Eqs. (17) and (14). Then the expressions in Eqs. (17) and (14) are written as, respectively

$$
\begin{gathered}
\mathbf{K} \cdot \dot{\mathbf{u}}(t)=\lambda \int_{V} \mathbf{B}^{T} \cdot\left[\lambda_{M} \dot{\boldsymbol{\sigma}}^{E M}(t)+\lambda_{\theta} \dot{\boldsymbol{\sigma}}^{E \theta}(t)\right] d V+\lambda \lambda_{\theta} \alpha \dot{\theta}(t) \int_{V} \mathbf{B}^{T} \cdot \mathbf{D} \cdot \mathbf{I} d V+\int_{V} \mathbf{B}^{T} \cdot \boldsymbol{\sigma}^{C}(t) d V \\
\dot{\boldsymbol{\rho}}(t)=\mathbf{D} \cdot \mathbf{B} \cdot \dot{\mathbf{u}}(t)-\lambda\left[\lambda_{M} \dot{\boldsymbol{\sigma}}^{E M}(t)+\lambda_{\theta} \dot{\boldsymbol{\sigma}}^{E \theta}(t)\right]-\lambda \lambda_{\theta} \alpha \dot{\theta}(t) \mathbf{D} \cdot \mathbf{I}-\boldsymbol{\sigma}^{C}(t)
\end{gathered}
$$

Then the residual stress can be updated by 


$$
\boldsymbol{\rho}(t+\Delta t)=\boldsymbol{\rho}(t)+\int_{t}^{t+\Delta t} \dot{\boldsymbol{\rho}}(t) d t
$$

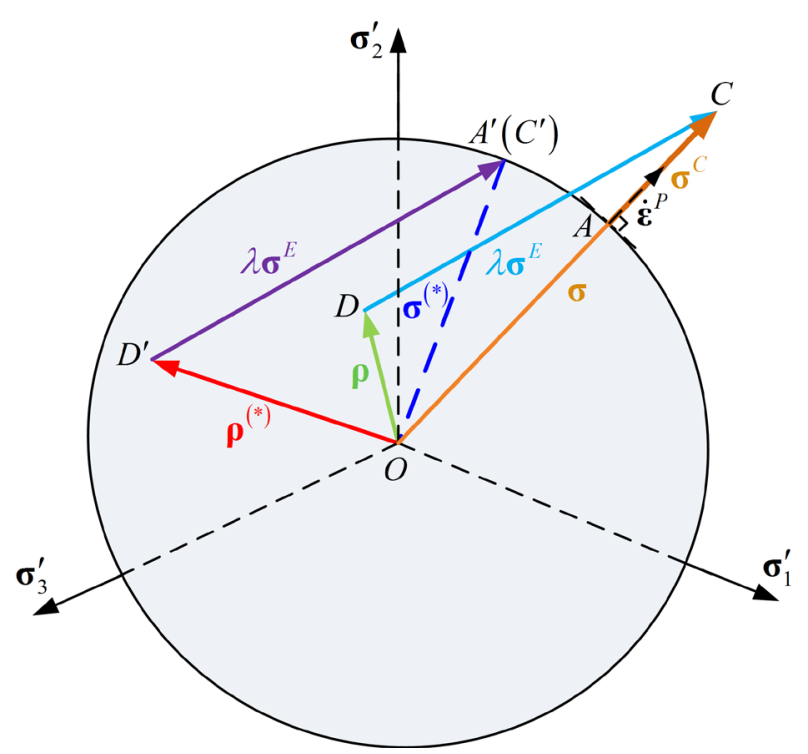

Fig. 3. Stress superposition schematic in the deviatoric plane.

Fig. 3 gives a stress superposition schematic of the SCM in the deviatoric plane. For a load vertex $i$ (or time point $\left.t_{i}\right)$, the total stress $\boldsymbol{\sigma}\left(t_{i}\right)$ at each Gauss point is determined by

$$
\boldsymbol{\sigma}\left(t_{i}\right)=\lambda \boldsymbol{\sigma}^{E}\left(t_{i}\right)+\boldsymbol{\rho}\left(t_{i}\right)=\lambda\left[\lambda_{M} \dot{\boldsymbol{\sigma}}^{E M}\left(t_{i}\right)+\lambda_{\theta} \dot{\boldsymbol{\sigma}}^{E \theta}\left(t_{i}\right)\right]+\boldsymbol{\rho}\left(t_{i}\right)
$$

233 As displayed in Fig. 3, the total stress $\boldsymbol{\sigma}\left(t_{i}\right)(\overrightarrow{O C})$ equals to the sum of residual stress $\boldsymbol{\rho}\left(t_{i}\right)(\overrightarrow{O D})$ and 234 fictitious elastic stress $\lambda \boldsymbol{\sigma}^{E}\left(t_{i}\right)(\overrightarrow{D C})$. The compensation stress $\boldsymbol{\sigma}^{C}\left(t_{i}\right)(\overrightarrow{A C})$ can be evaluated by the 235 following formulae:

$$
\boldsymbol{\sigma}^{C}\left(t_{i}\right)=\xi\left(t_{i}\right) \cdot \boldsymbol{\sigma}\left(t_{i}\right), \xi\left(t_{i}\right)=\left\{\begin{array}{cc}
\frac{\bar{\sigma}\left(t_{i}\right)-\sigma_{y}\left(\theta\left(t_{i}\right)\right)}{\bar{\sigma}\left(t_{i}\right)} & \left(\bar{\sigma}\left(t_{i}\right)>\sigma_{y}\left(\theta\left(t_{i}\right)\right)\right) \\
0 & \left(\bar{\sigma}\left(t_{i}\right) \leq \sigma_{y}\left(\theta\left(t_{i}\right)\right)\right)
\end{array}\right.
$$

237 where $\bar{\sigma}\left(t_{i}\right)$ is the von Mises stress at load vertex $i$. By substituting Eq. (22) into (18), the nodal displacement 238 rate $\dot{\mathbf{u}}\left(t_{i}\right)$ is obtained via solving Eq. (18). Next the updated residual stress $\boldsymbol{\rho}\left(t_{i}\right)$ can be calculated by Eqs. 239 (19) and (20).

\section{4. Numerical implementation of the SCM}

\subsection{Initial preparation}

Before the iterative process of the stress compensation method (SCM) begins, both the fictitious elastic 
stress fields at all the vertices of a loading domain and an initial load multiplier above shakedown limit need to be given. The fictitious elastic stress field can be obtained by combining some basic stress fields from a set of linear elastic solutions. For the convenience of programming, these linear elastic problems are respectively solved and then these calculated stress fields are stored in terms of vector. Considering that the temperature decreases the yield stress of materials, an initial load multiplier is evaluated by

$$
\lambda^{\mathrm{ini}}=\frac{\int_{V}\left(\sigma_{y_{0}} \sum_{i=1}^{m} \bar{\varepsilon}_{i}(\mathbf{x})\right) d V}{\int_{V}\left(\sum_{i=1}^{m} \boldsymbol{\sigma}^{E}\left(\mathbf{x}, t_{i}\right) \cdot \mathbf{\varepsilon}^{E}\left(\mathbf{x}, t_{i}\right)\right) d V}
$$

where $\sigma_{y_{0}}$ is the yield strength with respect to the lowest temperature; $\boldsymbol{\varepsilon}^{E}\left(\mathbf{x}, t_{i}\right)$ is the stain of the body under the fictitious elastic stress $\boldsymbol{\sigma}^{E}\left(\mathbf{x}, t_{i}\right)$; and $\bar{\varepsilon}_{i}(\mathbf{x})$ is the equivalent strain of $\boldsymbol{\varepsilon}^{E}\left(\mathbf{x}, t_{i}\right)$.

\subsection{Numerical implementation for shakedown analysis}

For a convex yield function in $\sigma-\theta$ space, shakedown analysis can be simplified by checking the shakedown state of structure under every load vertex vector $\mathbf{P}_{i}^{V}(\mathbf{x}) \quad(i=(1, \cdots, m))$ of the polyhedral loading domain in place of all loading paths. Then the static shakedown conditions presented in Eq. (8) need to be examined only at these $m$ load vertices. The following expressions are described as the incremental form.

Considering that Eqs. (18) and (19) are solved for every load vertex, we superpose these $m$ expressions at all the load vertices of a load cycle, then we get

$$
\sum_{i=1}^{m} \Delta \boldsymbol{\rho}\left(t_{i}\right)=\mathbf{D} \cdot \mathbf{B} \cdot \sum_{i=1}^{m} \Delta \mathbf{u}\left(t_{i}\right)-\lambda \sum_{i=1}^{m}\left[\lambda_{M} \Delta \boldsymbol{\sigma}^{E M}\left(t_{i}\right)+\lambda_{\theta} \Delta \boldsymbol{\sigma}^{E \theta}\left(t_{i}\right)\right]-\lambda \lambda_{\theta} \alpha \mathbf{D} \cdot \sum_{i=1}^{m} \Delta \theta\left(t_{i}\right) \mathbf{I}-\sum_{i=1}^{m} \boldsymbol{\sigma}^{C}\left(t_{i}\right)
$$

For simplification of notation, Eq. (24) is rewritten as

$$
\left\{\begin{array}{c}
\Delta \boldsymbol{\rho}=\mathbf{D} \cdot \mathbf{B} \cdot \Delta \mathbf{u}-\lambda \sum_{i=1}^{m}\left[\lambda_{M} \Delta \boldsymbol{\sigma}^{E M}\left(t_{i}\right)+\lambda_{\theta} \Delta \boldsymbol{\sigma}^{E \theta}\left(t_{i}\right)\right]-\lambda \lambda_{\theta} \alpha \mathbf{D} \cdot \sum_{i=1}^{m} \Delta \theta\left(t_{i}\right) \mathbf{I}-\sum_{i=1}^{m} \boldsymbol{\sigma}^{C}\left(t_{i}\right) \\
\Delta \boldsymbol{\rho}_{0}=\frac{1}{m} \Delta \boldsymbol{\rho}
\end{array}\right.
$$

where $\Delta \boldsymbol{\rho}_{0}$ is the residual stress increment. So the equilibrium equation in Eq. (18) and residual stress increment $\Delta \boldsymbol{\rho}_{0}$ are just solved once during a load cycle.

The two-level iterative scheme of the SCM is summarized as follows. For iteration $n$ in inner loop:

(1) For every load vertex $i, \boldsymbol{\sigma}^{(n)}\left(t_{i}\right)$ are calculated at all Gauss points of the body. 


$$
\boldsymbol{\sigma}^{(n)}\left(t_{i}\right)=\lambda^{(k)} \boldsymbol{\sigma}^{E}\left(t_{i}\right)+\boldsymbol{\rho}_{0}^{(n)}, \quad i=1,2, \cdots, m
$$

266 (2) Calculate the compensation stress $\boldsymbol{\sigma}^{C(n)}\left(t_{i}\right)$ via Eq. (22) for all load vertices of the cycle.

267 (3) Get the nodal displacement increment $\Delta \mathbf{u}^{(n+1)}$ by solving Eq. (27), and then calculate the residual stress increment $\Delta \boldsymbol{\rho}_{0}^{(n+1)}$ by Eq. (28). An updated residual stress $\boldsymbol{\rho}_{0}^{(n+1)}$ for next iteration is obtained by Eq. (29).

$$
\begin{gathered}
\mathbf{K} \cdot \Delta \mathbf{u}^{(n+1)}=\sum_{i=1}^{m}\left\{\lambda^{(k)} \int_{V} \mathbf{B}^{T} \cdot\left[\lambda_{M} \Delta \boldsymbol{\sigma}^{E M}\left(t_{i}\right)+\lambda_{\theta} \Delta \boldsymbol{\sigma}^{E \theta}\left(t_{i}\right)+\mathbf{D} \cdot \lambda_{\theta} \alpha \Delta \theta\left(t_{i}\right) \mathbf{I}\right] d V+\int_{V} \mathbf{B}^{T} \cdot \boldsymbol{\sigma}^{C(n)}\left(t_{i}\right) d V\right\} \\
\left\{\begin{array}{c}
\Delta \boldsymbol{\rho}^{(n+1)}=\mathbf{D} \cdot \mathbf{B} \cdot \Delta \mathbf{u}^{(n+1)}-\lambda^{(k)} \sum_{i=1}^{m}\left[\lambda_{M} \Delta \boldsymbol{\sigma}^{E M}\left(t_{i}\right)+\lambda_{\theta} \Delta \boldsymbol{\sigma}^{E \theta}\left(t_{i}\right)\right]-\lambda^{(k)} \mathbf{D} \cdot \sum_{i=1}^{m} \lambda_{\theta} \alpha \Delta \theta\left(t_{i}\right) \mathbf{I}-\sum_{i=1}^{m} \boldsymbol{\sigma}^{C(n)}\left(t_{i}\right) \\
\Delta \boldsymbol{\rho}_{0}^{(n+1)}=\frac{1}{m} \Delta \boldsymbol{\rho}^{(n+1)}
\end{array}\right.
\end{gathered}
$$

$$
\boldsymbol{\rho}_{0}^{(n+1)}=\boldsymbol{\rho}_{0}^{(n)}+\Delta \boldsymbol{\rho}_{0}^{(n+1)}
$$

(4) Check the convergence of $\boldsymbol{\sigma}^{C(n)}\left(t_{i}\right)$, and repeat the steps 1-3 till the convergence is reached. The convergence criterion is defined by

$$
\left|\xi^{(n+1)}\left(t_{i}\right)-\xi^{(n)}\left(t_{i}\right)\right| \leq \text { tol } 1
$$

where tol 1 is a predefined tolerance parameter.

The outer loop aims to calculate load multipliers. For iteration $k$ in outer loop:

(1) Carry out the inner loop till the convergence is in reach.

(2) Record the maximum value $\xi_{\max }^{(k+1)}$ of the variable $\xi^{(n+1)}\left(t_{i}\right)$ over a load cycle, that is

(3) The convergence rate is examined:

$$
\xi_{\max }^{(k+1)}=\max \left(\xi^{(n+1)}\left(t_{i}\right)\right)
$$

where $\omega$ is a convergence parameter. If Condition (32) is satisfied, the load multiplier $\lambda^{(k)}$ is corrected by

$$
\frac{\xi_{\max }^{(k+1)}}{\xi_{\max }^{(k)}} \leq t o l 2 \text {, and } \omega>0.1
$$

and $\omega$ is reduced, i.e. $\omega=\omega / 2$. Otherwise, the updated load multiplier $\lambda^{(k+1)}$ is obtained by

$$
\lambda^{(k+1)}=\frac{\lambda^{(k)}\left(1-\frac{\omega}{2} \cdot \xi_{\max }^{(k+1)}\right)}{\left(1-\omega \cdot \xi_{\max }^{(k+1)}\right)}
$$

$$
\lambda^{(k+1)}=\lambda^{(k)}\left(1-\omega \cdot \xi_{\max }^{(k+1)}\right)
$$


287 (4) Check whether the value of $\xi_{\max }^{(k+1)}$ approaches to zero within a desired tolerance tol3.

$$
\xi_{\max }^{(k+1)} \leq \text { tol3 }
$$

(5) Repeat the steps 1 4 till the convergence condition in Eq. (35) holds. Finally, the shakedown limit multiplier $\lambda_{\mathrm{sh}}$ is obtained

$$
\lambda_{\mathrm{sh}}=\lambda^{(k+1)}
$$

\section{5. Numerical applications and discussion}

The numerical procedure is incorporated into ABAQUS software via the user subroutines UMAT and

URDFIL. Different FE models, including plane stress element, axisymmetric element and three-dimensional solid element, are considered and analyzed to verify the availability and to demonstrate the performance of the developed numerical method for shakedown analysis of structures considering the temperature effect on yield strength. Both linear and nonlinear yield stress functions with respect to temperature are considered.

\subsection{Verification of the method for plane stress element by the Bree problem}

The Bree problem is a typical benchmark example for uniaxial shakedown and ratchet analysis of structure under thermomechanical loading. Some authors (Bree, 1967; Bradford et al., 2014) have studied the shakedown boundary considering the effect of mean temperature on yield strength analytically. In these analyses, the elastoplastic material with different yield strengths off-load and on-load is considered, and the temperature gradient across can wall is small enough thus the yield stress is uniform over the whole structure. However, for actual structures, the temperature difference among different material points may be large. It is necessary to determine these shakedown boundaries considering the effect of temperature gradient on yield strength.

As displayed in Fig. 4, the plate is subject to the cyclic temperature difference $\Delta \theta(t)$ linearly distributed along its width and the constant axial tension $\sigma_{P}$, and the thermal dilation deformation is restricted via plane condition. Under this condition, the through-wall temperature gradient causes bending stress varying between the maximum value $\sigma_{t}$ and zero. The main material parameters of the plate at the room temperature of $20^{\circ} \mathrm{C}$ that represents the off-load case are given in Table 1. The plate is discretized with 200 quadratic plane stress

311 elements. In the following two sub-sections, the shakedown analyses of the Bree problem considering two kinds 312 of temperature-dependent yield stresses are studied using the developed SCM. 


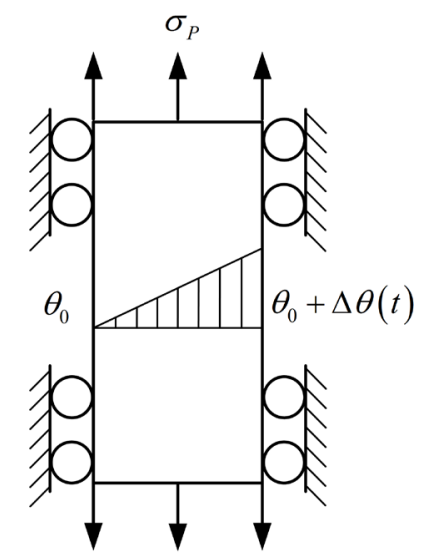

Table 1 Main material parameters of the plate at the room temperature of $20^{\circ} \mathrm{C}$.

\begin{tabular}{|c|c|c|c|}
\hline $\begin{array}{c}\text { Thermal expansion } \\
\text { coefficient } \alpha\end{array}$ & Yield stress $\sigma_{y_{0}}$ & Young's modulus $E$ & Poisson's ratio $v$ \\
\hline $5 \times 10^{-5} /{ }^{\circ} \mathrm{C}$ & $360 \mathrm{MPa}$ & $208 \mathrm{GPa}$ & 0.3 \\
\hline
\end{tabular}

\subsubsection{Effect of mean temperature on yield strength}

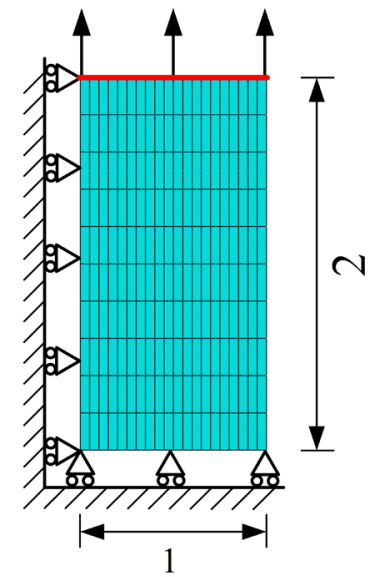

Fig. 4. Geometry of the plate and its FE model.

We assume that the plate suffers large temperature variation between on-load and off-load cases but the temperature gradient across the width is small enough to be ignored. To estimate the temperature effect, we assume the yield stress $\sigma_{y}$ decreases to $\sigma_{y}=0.75 \sigma_{y_{0}}$ at high temperature, and the other material parameters keep constant.

The analytical solution of shakedown boundary curve is as follows (Bree, 1967):

$$
\left\{\begin{array}{c}
\frac{\sigma_{t}}{\sigma_{y_{0}}}=\frac{\sigma_{y}}{\sigma_{y_{0}}}+1 \\
\frac{\sigma_{P}}{\sigma_{y_{0}}}+\frac{\left(\sigma_{t} / \sigma_{y_{0}}+\sigma_{y} / \sigma_{y_{0}}-1\right)^{2}}{4 \sigma_{t} / \sigma_{y_{0}}}=\frac{\sigma_{y}}{\sigma_{y_{0}}} \\
\frac{\sigma_{P}}{\sigma_{y_{0}}}=\frac{\sigma_{y}}{\sigma_{y_{0}}}
\end{array}\right.
$$$$
\begin{gathered}
\left(0 \leq \frac{\sigma_{P}}{\sigma_{y_{0}}} \leq \frac{\sigma_{y}}{\sigma_{y}+\sigma_{y_{0}}}\right) \\
\left(\frac{\sigma_{y}}{\sigma_{y}+\sigma_{y_{0}}} \leq \frac{\sigma_{P}}{\sigma_{y_{0}}} \leq \frac{\sigma_{y}}{\sigma_{y_{0}}}\right) \\
\left(0 \leq \frac{\sigma_{t}}{\sigma_{y_{0}}} \leq 1-\frac{\sigma_{y}}{\sigma_{y_{0}}}\right)
\end{gathered}
$$

The SCM is utilized to evaluate these shakedown limits of the plate under different combinations of constant mechanical load and varying thermal load. Both the calculated numerical shakedown domain and the analytical solutions are displayed in Fig. 5. The boundary of shakedown domain considering the temperature effect is divided into three regions, which correspond to $\mathrm{AB}$ for alternating plasticity limit, $\mathrm{BC}$ for ratchet limit, and $\mathrm{CD}$ 
for plastic collapse limit. The numerical results obtained via the SCM agree well with the analytical solution, especially in the ratchet and plastic collapse regions. For a comparison, the shakedown domain of the plate with temperature-independent yield stress is also added in Fig. 5. For CD region, the shakedown limit is $0.75 \sigma_{P} / \sigma_{y_{0}}$, which is in proportion to the yield strength $\sigma_{y}=0.75 \sigma_{y_{0}}$ corresponding to the highest temperature. Significant differences of the shakedown domains explain the importance of considering the effect of mean temperature on yield strength when assessing the structure undergoing a high temperature variation between off-load and on-load cases.

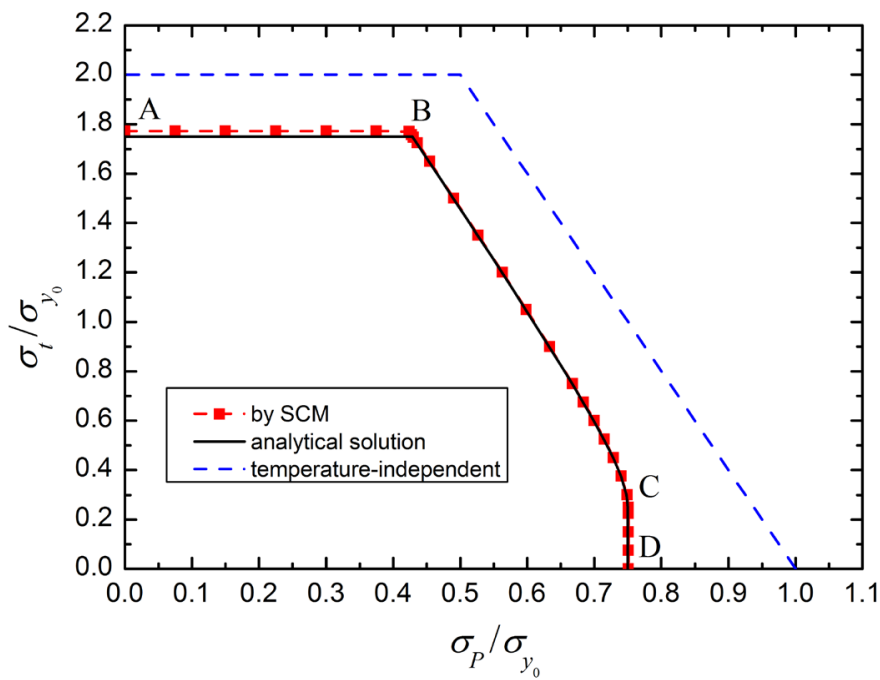

Fig. 5. Shakedown domain of the plate under a constant uniaxial tension and a varying thermal load considering mean temperature effect on yield strength.

\subsubsection{Effect of temperature gradient on yield strength}

Here, the yield stress $\sigma_{y}(\theta)$ of the plate is assumed as the linear function of temperature $\theta$ :

$$
\sigma_{y}(\theta)=\sigma_{y_{0}}-c \cdot\left(\theta-20^{\circ} \mathrm{C}\right)
$$

340 where $c$ is a parameter.

341 (1) Analytical solutions

342 a) Alternating plasticity mechanism

As given in Appendix A, the dimensionless shakedown limit $\sigma_{t} / \sigma_{y_{0}}$ dominated by alternating plasticity mechanism can be determined by

$$
\frac{\sigma_{t}}{\sigma_{y_{0}}}=\frac{2 E \alpha}{2 c+E \alpha}
$$


b) Ratcheting mechanism

As described in Appendix B, the dimensionless shakedown limit dominated by ratcheting mechanism can 348 be determined by

Combining Eq. (39) and Eq. (40), we can obtain the coordinate of the intersection of alternating plasticity and ratchet limit boundaries:

where $\sigma_{P \text { int }} / \sigma_{y_{0}}$ is the dimensionless constant mechanical load of the intersection point.

354 (2) Numerical results by the SCM

We adopt the SCM to perform shakedown analysis of the Bree problem considering the temperaturedependent yield stress with different values of $c$. The yield stress is updated according to the actual load factor after each iteration. As some results, the shakedown domains of the plate obtained by the SCM with the values of $c$ equaling to $0,0.5,1.0,1.5 \mathrm{MPa} /{ }^{\circ} \mathrm{C}$ are presented in Fig. 6 , respectively. For the purpose of comparison, the analytical solutions for these cases are also added in this figure. It is obvious that the calculated results by the SCM agree well with the analytical solution, and the value of $c$ has significant influence on these shakedown domains, which demonstrates the significance of considering the temperature effect on yield strength for shakedown problem in practical engineering.

In order to explore the relationship between these shakedown limits and the values of $c$, the vertical and horizontal coordinates of the intersection point of alternating plasticity limit boundary and ratchet limit boundary in the dimensionless coordinate system $\sigma_{t} / \sigma_{y_{0}}-\sigma_{P} / \sigma_{y_{0}}$ are calculated for parameter $c$ varying from 0.0 to 2.0 $366 \mathrm{MPa} /{ }^{\circ} \mathrm{C}$. Fig. 7 and Fig. 8 show the curves of the dimensionless thermal load $\sigma_{t} / \sigma_{y_{0}}$ and mechanical load $367 \sigma_{P} / \sigma_{y_{0}}$ at the intersection point versus parameter $c$, respectively, each of which includes the numerical results by the SCM and the analytical solutions. 


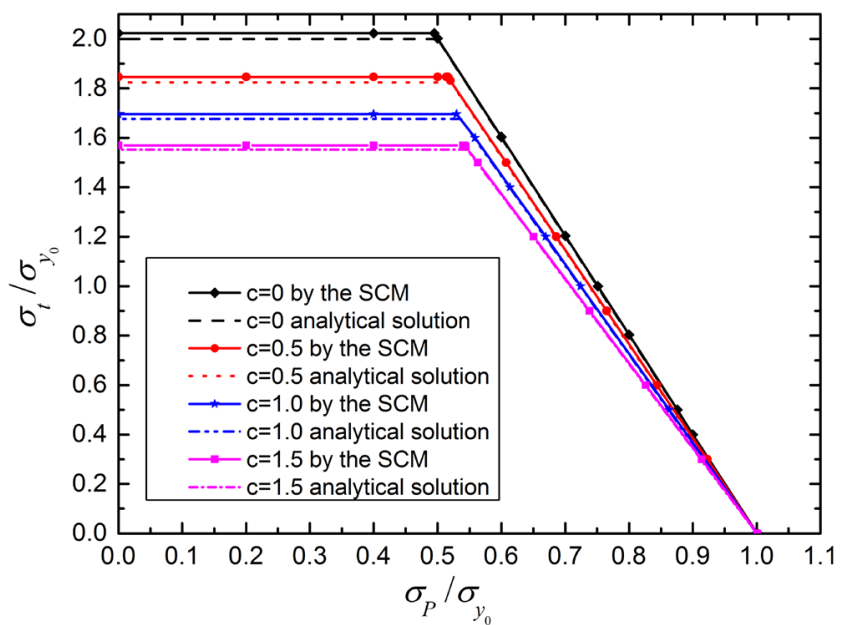

Fig. 6. Analytical solutions and numerical results by the SCM for the shakedown domains of the Bree problem with different values of parameter $c$.

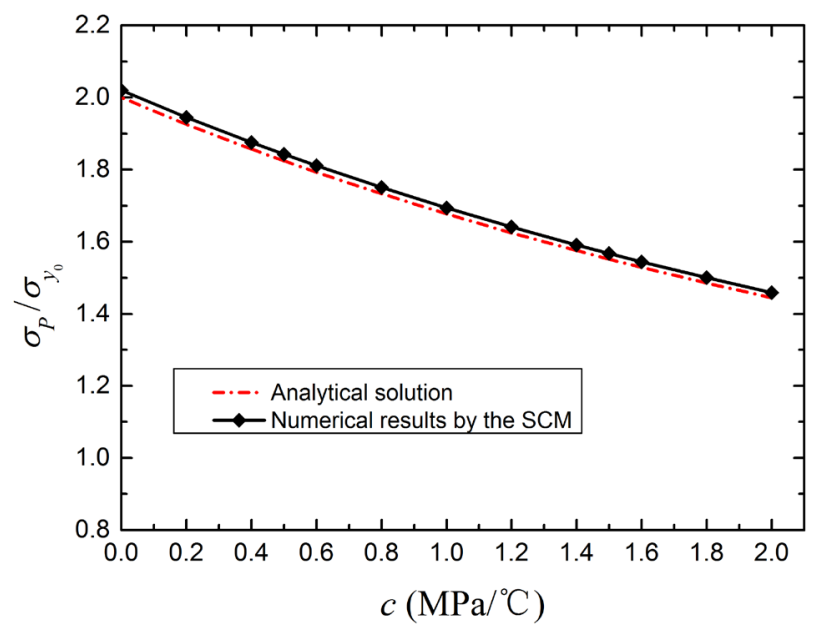

Fig. 7. Dimensionless thermal load at the intersection point versus parameter $c$.

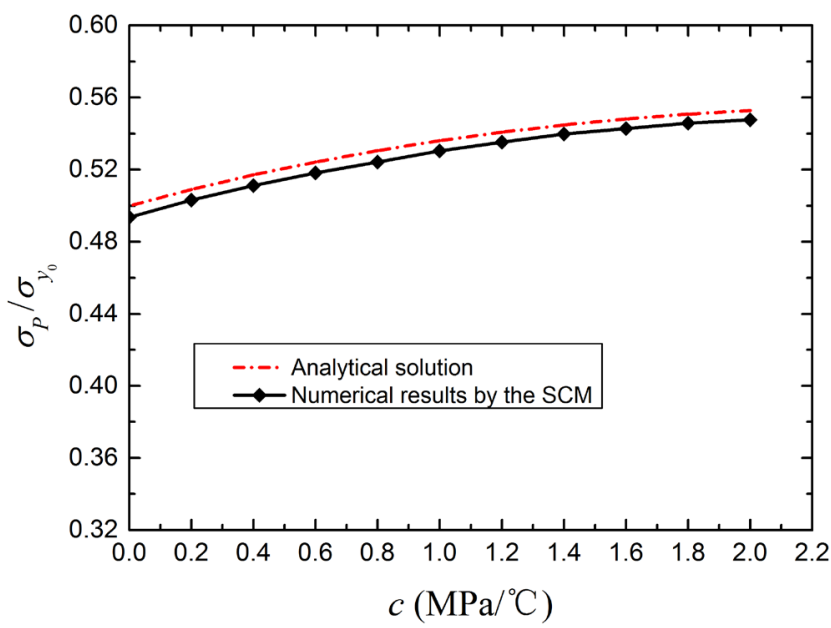

Fig. 8. Dimensionless mechanical load at the intersection point versus $c$. 


\subsection{Verification of the method for axisymmetric element by a thick-walled cylinder}

Here, we evaluate shakedown domain of a thick-walled cylinder which is displayed in Fig. 9. The outer and inner radii of the cylinder are $R_{\mathrm{o}}$ and $R_{\mathrm{i}}$, respectively. The structure is under the constant internal pressure $P$ and the variable temperature field with nonlinear distribution across its thickness:

$$
\theta(r, t)=\bar{\theta}(t) \frac{\ln \left(R_{\mathrm{o}} / r\right)}{\ln \left(R_{\mathrm{o}} / R_{\mathrm{i}}\right)} \quad\left(\theta_{0} \leq \bar{\theta}(t) \leq \theta\right)
$$

Considering the axial symmetry of loading and structure, the axisymmetric model is established for FE analysis (see Fig. 9). Plane condition and equivalent axial tension induced by internal pressure are applied to the end face. The discretization of the cylinder consists of 60 quadratic reduced axisymmetric elements (ABAQUS CAX8R) with 20 elements in the radial direction.

This example has been studied by some authors (Gokhfeld and Charniavsky, 1980; Vu and Staat, 2007). For the purpose of comparison, we adopt the same material parameters and yield stress functions as those in $\mathrm{Vu}$ and Staat (2007). The main material parameters of the thick-walled cylinder are listed in Table 2. The linear and nonlinear yield stress functions of temperature are written, respectively as

$$
\begin{gathered}
\sigma_{y}^{\text {linear }}(\theta)=\sigma_{y_{0}}\left[1-A \cdot\left(\theta-\theta_{0}\right)\right] \\
\sigma_{y}^{\text {nonlinear }}(\theta)=\sigma_{y_{0}}\left[1-A \cdot\left(\theta-\theta_{0}\right)-B \cdot\left(\theta-\theta_{0}\right)^{2}\right]
\end{gathered}
$$

where $\sigma_{y_{0}}=190 \mathrm{MPa}$ is the yield stress at temperature $\theta_{0} ; A=8.3 \times 10^{-4}{ }^{\circ} \mathrm{C}^{-1}$ and $B=7.41 \times 10^{-6}{ }^{\circ} \mathrm{C}^{-2}$.

The shakedown analyses for the thick-walled cylinder with three kinds of yield stress functions were completed by the SCM. The numerical results obtained by the SCM and the solutions from Vu and Staat (2007) are presented in Fig. 10. The good agreement between these two results demonstrates the validity of the algorithm procedure.
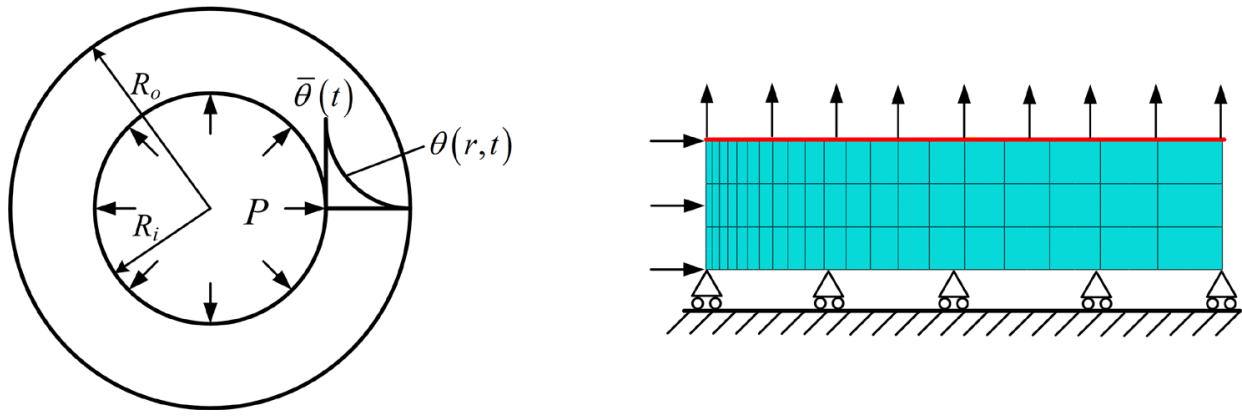

Fig. 9. Thick-walled cylinder and FE model. 
Table 2 Main material parameters of the thick-walled cylinder.

\begin{tabular}{|c|c|c|c|}
\hline $\begin{array}{c}\text { Thermal expansion } \\
\text { coefficient } \alpha\end{array}$ & Yield stress $\sigma_{y_{0}}$ & Young's modulus $E$ & Poisson's ratio $v$ \\
\hline $2.34 \times 10^{-5} /{ }^{\circ} \mathrm{C}$ & $190 \mathrm{MPa}$ & $71 \mathrm{GPa}$ & 0.34 \\
\hline
\end{tabular}

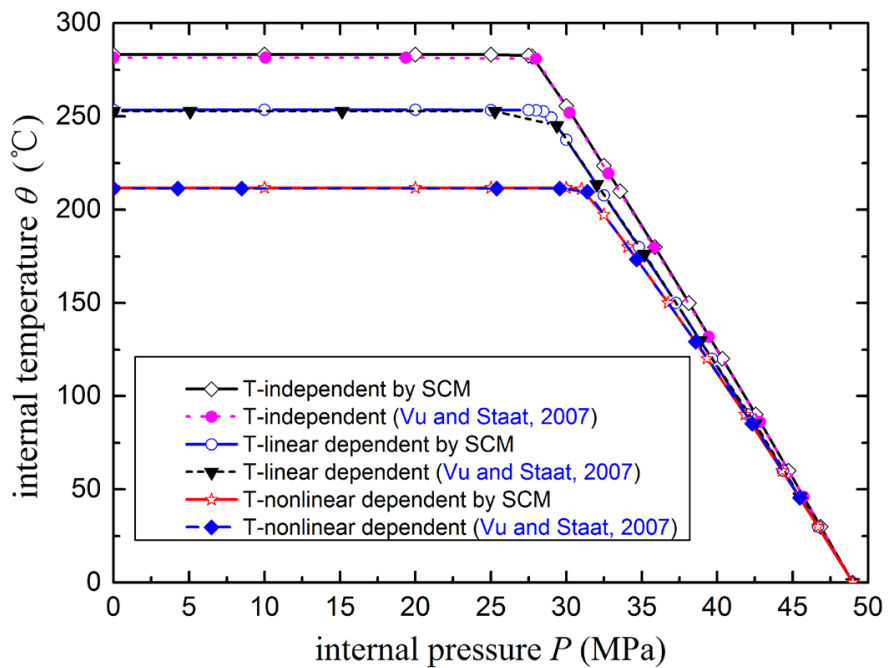

Fig. 10. Shakedown domains of the thick-walled cylinder with different yield stress functions.

\subsection{Applications to engineering structure by a pipe with oblique nozzle}

To verify the applicability of the developed SCM for complex structure considering the temperature effect on yield strength, an actual pipe with oblique nozzle is analyzed. Fig. 11 shows the one-half geometric model of the structure, and its main geometric parameters are given in Table 3. The hot fluid flows inside the pipe and the nozzle. The structural component works under high temperature and pressure. When the equipment shuts down or starts up, the pipe and the nozzle suffer from large temperature variation and varying pressure, and the material property varies with the temperature. Here, we calculate the shakedown domains of the structure under varying thermal and mechanical loads for two different loading cases with the consideration of the effect of temperature on yield stress. 


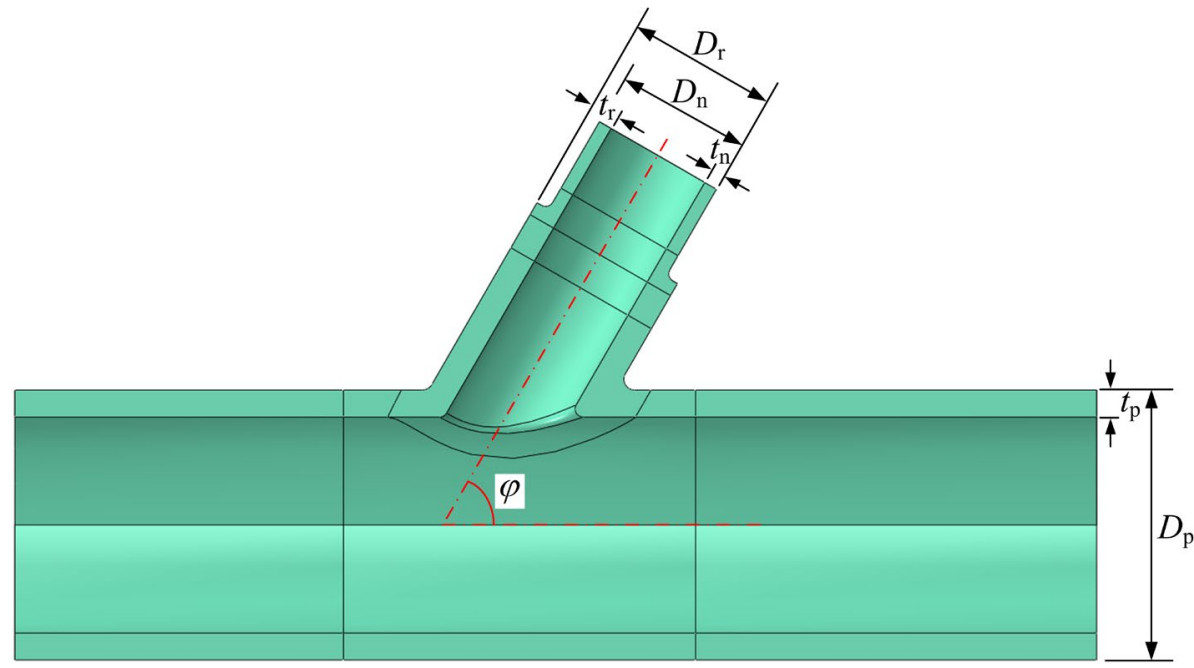

Fig. 11. One-half geometric model of the pipe with oblique nozzle.

Table 3 Main geometric parameters of the pipe with oblique nozzle.

\begin{tabular}{lll}
\hline Component & Parameters & Value \\
\hline \multirow{2}{*}{ Pipe } & Outer diameter $D_{\mathrm{p}}$ & $200 \mathrm{~mm}$ \\
& Thickness $t_{\mathrm{p}}$ & $20 \mathrm{~mm}$ \\
\multirow{3}{*}{ Oblique nozzle } & Outer diameter $D_{\mathrm{n}}$ & $100 \mathrm{~mm}$ \\
& Thickness $t_{\mathrm{n}}$ & $10 \mathrm{~mm}$ \\
\multirow{2}{*}{ Reinforced oblique nozzle } & Angle $\varphi$ & $60^{\circ}$ \\
& Outer diameter $D_{\mathrm{r}}$ & $120 \mathrm{~mm}$ \\
Round fillet weld & Thickness $t_{\mathrm{r}}$ & $20 \mathrm{~mm}$ \\
& Outside radius $R$ & $8 \mathrm{~mm}$ \\
& Inside radius $r$ & $6 \mathrm{~mm}$ \\
\hline
\end{tabular}

Fig. 12 gives the detailed information about FE model of the structure, which consists of 3170 elements and 16928 nodes. The symmetric displacement constraints are applied to the symmetry plane. Plane conditions and equivalent uniform tensions induced by internal pressure are applied to ends of the pipe and the nozzle. For transient heat transfer analysis, 3170 quadratic brick elements are adopted to calculate the temperature field; and for structural static analysis, 3170 reduced integrated quadratic brick elements are employed to calculate the stress field.

The temperature $\theta_{0}$ of the outside air keeps constant and the temperature history $\theta(t)=\theta_{0}+\Delta \theta(t)$ of the inside fluid follows the curve in Fig. 13. The initial temperature and environment temperature of the structure are both $\theta_{0}=20{ }^{\circ} \mathrm{C}$. The working pressure is $P_{0}=16.5 \mathrm{MPa}$. The pipe with oblique nozzle is made of chromium molybdenum steel (A387Cr12, ASTM). Some thermal and mechanical material parameters are given in Table 
4. Here, we only consider the temperature effect on yield strength, and the relation expression is as follows:

$$
\sigma_{y}(\theta)=\sigma_{y_{0}}+3 \mathrm{MPa}-0.15 \mathrm{MPa} /{ }^{\circ} \mathrm{C} \times \theta
$$

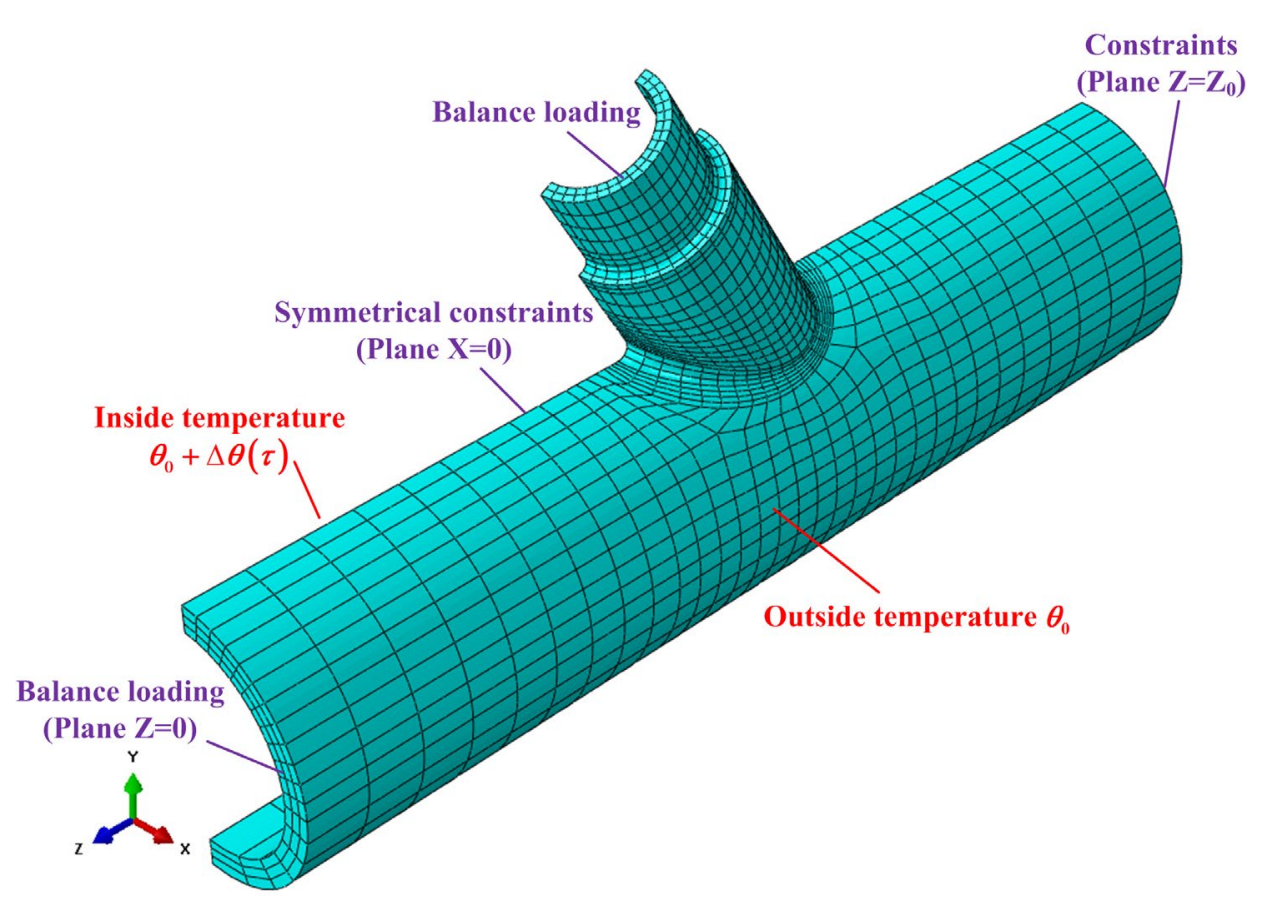

Fig. 12. FE model of the pipe with oblique nozzle.

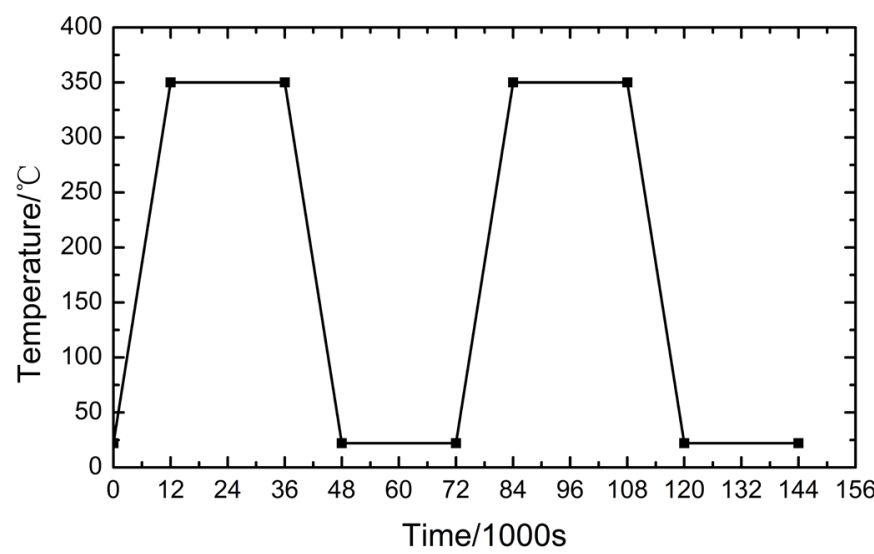

Fig. 13. Temperature history of the inside fluid.

Firstly, the temperature filed history of the structure is calculated via the transient heat transfer analysis. Then, by setting the obtained temperature filed history as predefined field, the thermal elastic stress field history is calculated via the structural stress analysis. Node 6308 and node 5451 located respectively on the outside and inside surfaces are selected as a representation to show the temperature histories of the outside and inside surfaces of the structure. As a result, their temperature histories are displayed in Fig. 14. It can be observed from 
Fig. 14 that the structure suffers from the maximum temperature gradient at the moment of $t=12000 \mathrm{~s}$. Thus the maximum thermal elastic stress of the pipe occurs at this moment. The von Mises thermal and mechanical stress fields of the pipe under the single thermal load and the single working pressure are shown in Fig. 15 (a) and (b),

Table 4 Main material parameters of the pipe with oblique nozzle.

\begin{tabular}{lc}
\multicolumn{2}{l}{ Table 4 Main material parameters of the pipe with oblique nozzle. } \\
\cline { 2 - 2 } Parameters & Value \\
\hline Thermal expansion coefficient $\alpha$ & $2.0 \times 10^{-5} /{ }^{\circ} \mathrm{C}$ \\
Thermal conductivity $k$ & $20 \mathrm{~W} /\left(\mathrm{m} \cdot{ }^{\circ} \mathrm{C}\right)$ \\
Specific heat capacity $c$ & $440 \mathrm{~J} /\left(\mathrm{kg} \cdot{ }^{\circ} \mathrm{C}\right)$ \\
Transfer coefficient pipe-air $h_{1}$ & $300 \mathrm{~W} /\left(\mathrm{m}^{2} \cdot{ }^{\circ} \mathrm{C}\right)$ \\
Transfer coefficient pipe-fluid $h_{2}$ & $800 \mathrm{~W} /\left(\mathrm{m}^{2} \cdot{ }^{\circ} \mathrm{C}\right)$ \\
Density $\rho$ & $7800 \mathrm{~kg} / \mathrm{m}^{3}$ \\
Yield stress $\sigma_{y}$ & $240 \mathrm{MPa}$ \\
Young's modulus $E$ & $2.1 \times 10^{5} \mathrm{MPa}$ \\
Poisson's ratio $v$ & 0.3 \\
\hline
\end{tabular}
respectively.

The total elastic stress of the structure consists of two components: $\sigma_{\theta}$ denotes the thermal stress corresponding to the temperature load $\theta$; and $\sigma_{P}$ denotes the mechanical stress caused by the internal pressure $P$. As displayed in Fig. 16, two types of loading cases are considered. For loading case I, thermal load and internal pressure vary independently. For loading case II, thermal load is cyclic and internal pressure keeps constant. The SCM is employed to determine the shakedown limits of this pipe for two loading cases considering different ratios of the two stress components.

The shakedown domains of the pipe with oblique nozzle considering temperature-independent and temperature-dependent yield strengths for two loading cases are all displayed in Fig. 17. For the loading case I, the alternating plasticity mechanism is decisive for the shakedown boundaries $\mathrm{AD}$ and $\mathrm{A}$ 'D. For the loading case II, the shakedown boundaries are divided into two regions i.e., AB or A'B' for alternating plasticity limit, and $\mathrm{BC}$ or B'C for ratchet limit. For both loading case I and loading case II, the shakedown domains are narrowed a lot when the effect of temperature on yield strength is taken into consideration. It is worth noting that, for the alternating plasticity regions $\mathrm{AB}$ and $\mathrm{A}^{\prime} \mathrm{B}$ ', the shakedown limit is decided by the maximum thermal stress of material point that undergoes high temperature. The high temperature leads to the reduction of the yield strength, therefore, the shakedown limit is largely decreased. The points $\mathrm{D}$ and $\mathrm{C}$ respectively denote the 
456 shakedown limit and plastic collapse limit of the structure under single pressure, and thus the temperaturedependent yield stress has no influence on them. These results show the significance of considering temperature effect on yield strength when assessing the safety of a structure operating under high temperature variation. On the other hand, if the variation range of operating temperature of the structure approaches to zero, the constant yield strength can be used to simplify the calculation.

Fig. 18 gives the typical convergence process of shakedown load multipliers when using the SCM to perform shakedown analysis of the pipe considering the temperature-dependent yield strength. Over the whole process, only one decomposition of the global stiffness matrix is carried out, which largely enhances the calculation efficiency of the SCM. The CPU time for each iteration of the SCM is about one quarter of that for a complete elastic FE analysis. The CPU time for completing a shakedown analysis is about $250 \mathrm{~s}$ using the Intel Core i7 processor with $3.39 \mathrm{GHz}$ and $16 \mathrm{~GB}$ RAM.

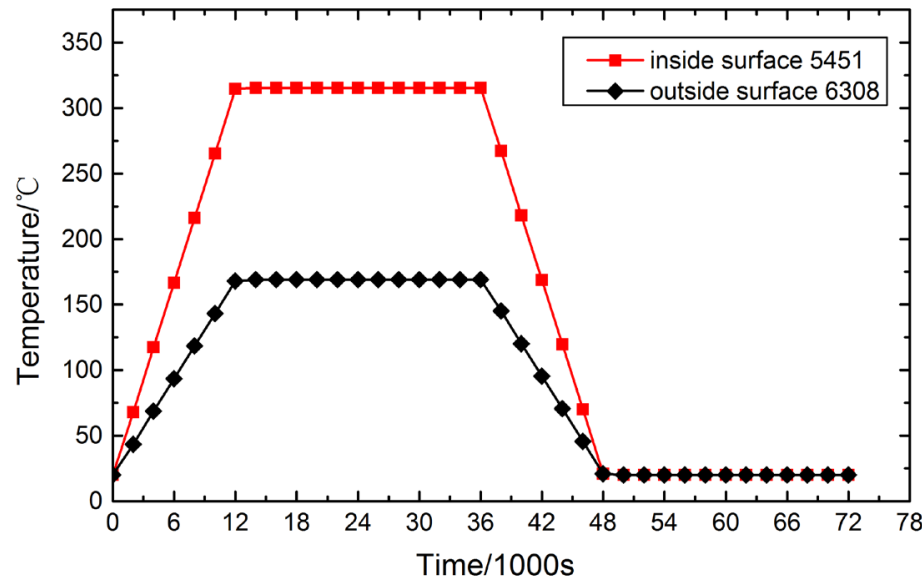

Fig. 14. Temperature histories of node 5451 and node 6308 .
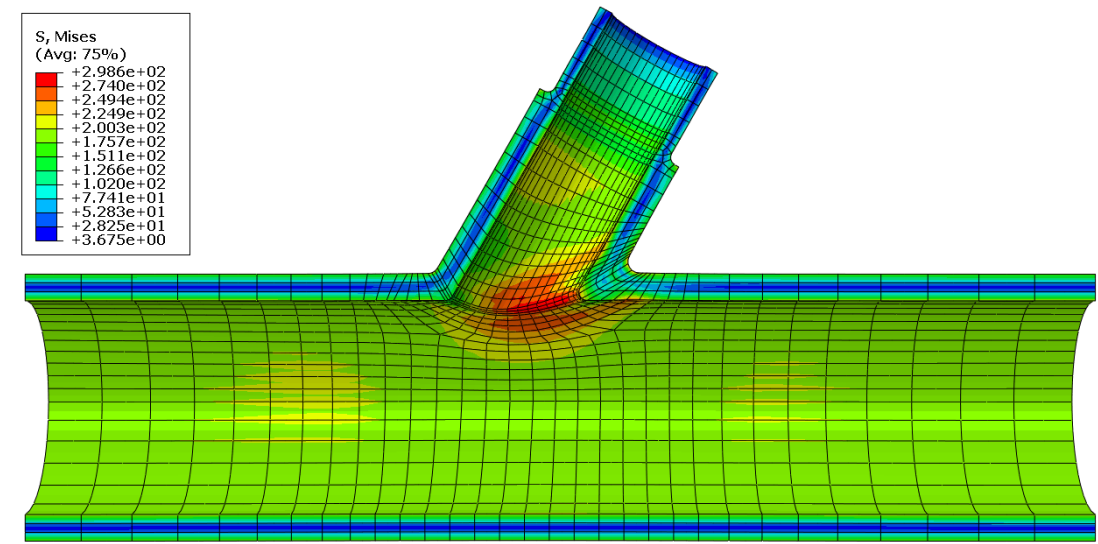

(a) Thermal stress field at the moment of $t=12000 \mathrm{~s}$ 


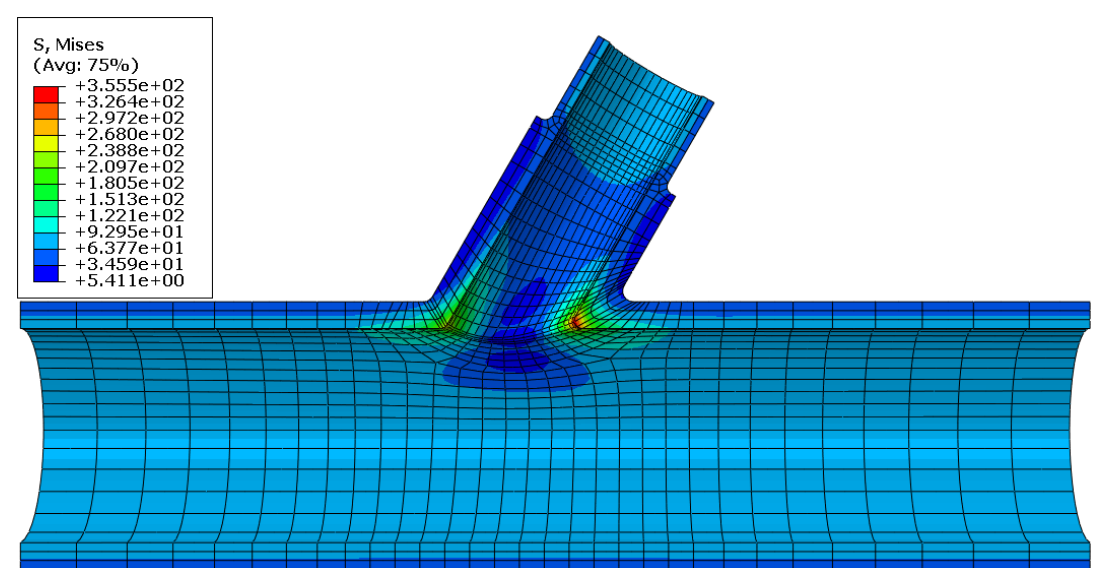

(b) Mechanical stress field

Fig. 15. Von Mises stress fields of the pipe with oblique nozzle.

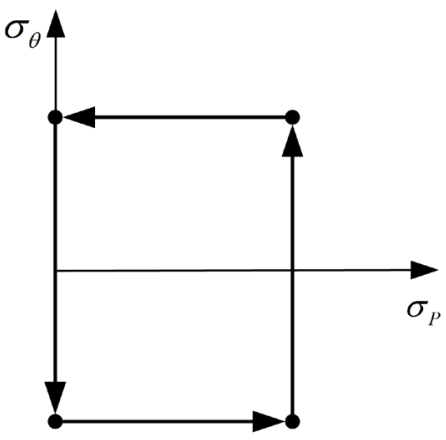

Loading case I

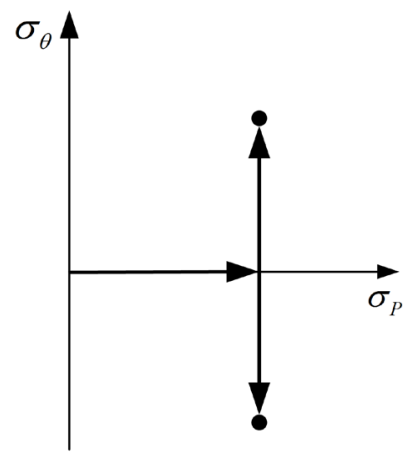

Loading case II

Fig. 16. Two loading cases for shakedown analysis.

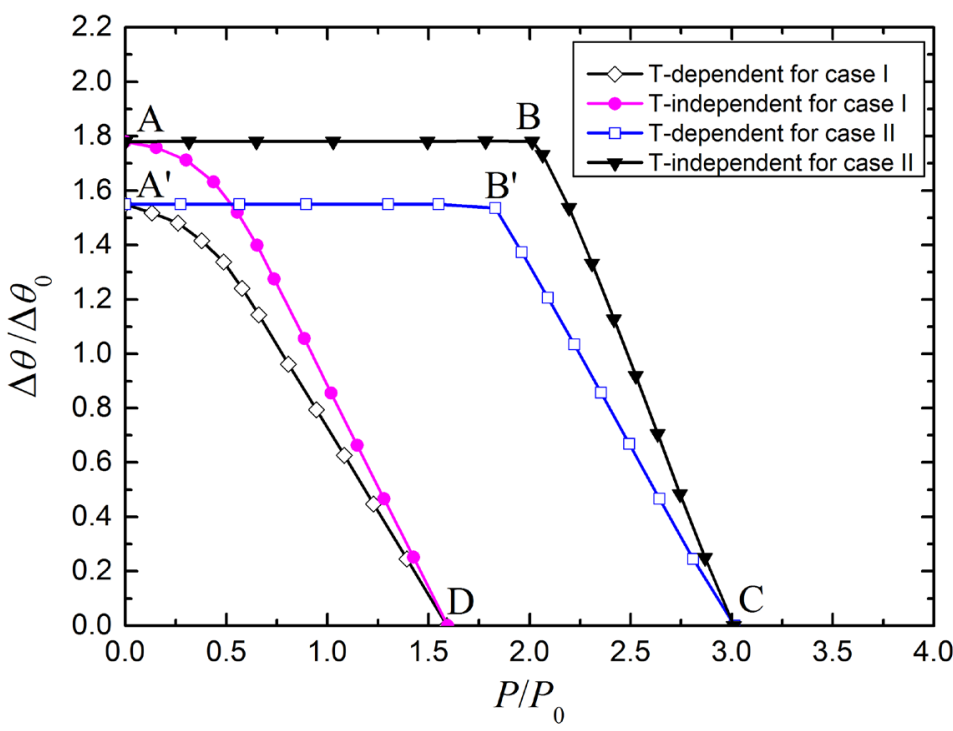

Fig. 17. Shakedown domains of the pipe with oblique nozzle considering temperature-dependent and temperature-independent yield strengths under two loading cases. 


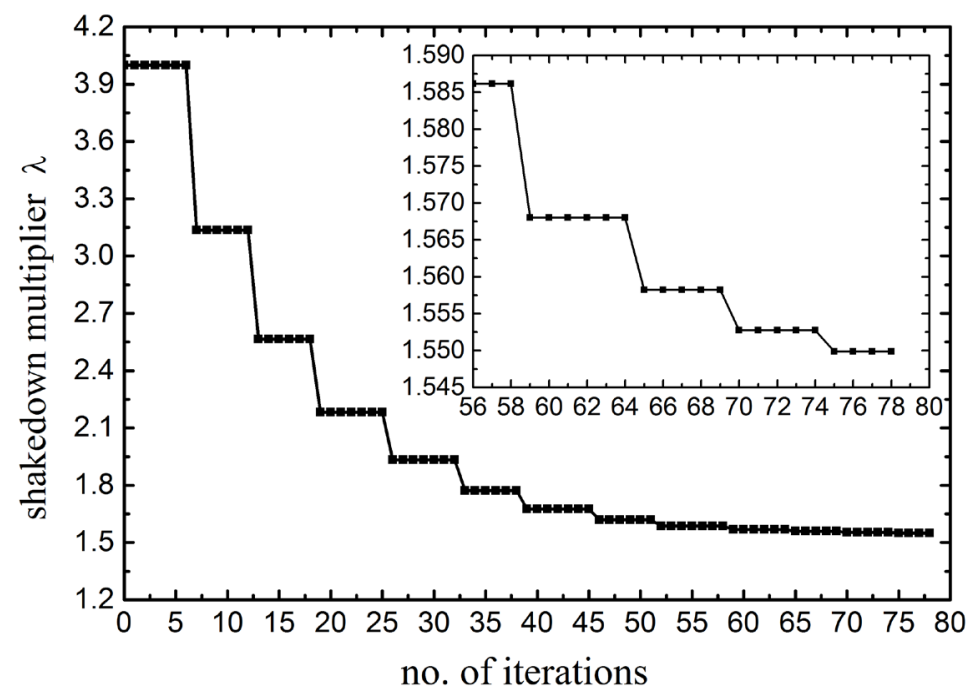

Fig. 18. Typical convergence process of shakedown load multipliers by the SCM.

\section{Conclusions}

This paper proposes theoretical and numerical aspects of the stress compensation method (SCM) to provide an efficient and accurate approach for shakedown analysis of elastic-plastic structures made of materials with temperature-dependent yield strength under complex thermomechanical loading system. Two-dimensional and three-dimensional numerical examples considering different yield stress functions with respect to temperature are solved and analyzed. The primary remarks of this paper are concluded as follows.

1. Based on the extended Melan's theorem, numerical formulation and algorithm of the SCM are established for shakedown analysis of elastic-plastic structures considering the effect of temperature on yield strength. The yield strength is updated according to the current temperature of material point during each iteration. Both the linear and nonlinear yield stress functions are considered.

2. Instead of solving a mathematical programming problem, the SCM for shakedown analysis just conducts a sequence of iterative calculations of FE analyses, where only one decomposition of global stiffness matrix is performed. The numerical procedure is incorporated into ABAQUS platform via the user subroutines UMAT and URDFIL, which make it become a general utility tool for shakedown analysis of complex engineering structures.

3. The shakedown domains of the Bree problem considering the effects of mean temperature and temperature gradient on the yield stress as well as of a thick-walled cylinder considering the yield stress as the linear and nonlinear functions of temperature are obtained by the numerical and analytical approaches. The numerical results by the SCM agree well with the analytical solutions and the results from literatures, which 
show good accuracy of the presented SCM. Moreover, the application of the SCM to a pipe with oblique nozzle demonstrates that it has high calculation efficiency for large-scale engineering problems with temperature-dependent yield strength.

4. The temperature effect on yield strength of material narrows the shakedown domain of a structure under cyclic thermomechanical loading to some degree, which depends on the temperature distribution and failure mechanism of the structure. For a structure with evenly distributed temperature along the thickness, the shakedown limit dominated by plastic collapse mechanism is in proportion to the yield strength at the highest temperature, while the shakedown limit dominated by alternating plasticity mechanism is approximately equal to the average value of shakedown limits using the minimum and maximum yield stresses. For a structure with gradient temperature along the thickness, the temperature-dependent yield strength has greater influences on the shakedown limit dominated by alternating plasticity mechanism than that dominated by ratcheting mechanism. It is very necessary to take into consideration of the temperature effect on yield strength of material when assessing the shakedown behavior of a structure operating at high temperature or undergoing large temperature difference.

\section{Acknowledgements}

This work is supported by the National Natural Science Foundation of China (Grant No. 11672147) and the National Science Foundation for Distinguished Young Scholars of China (Grant No. 11325211).

\section{Appendix A: Alternating plasticity mechanism}

As given in Bree (1967), the alternating plasticity limit of the Bree problem considering the yield strength as linear function of temperature can be calculated by

$$
\sigma_{t}=\sigma_{y_{0}}+\sigma_{y}(\theta)
$$

Considering that the thermal stress is $\sigma_{t}=E \alpha \cdot \Delta \theta / 2$ and the temperature-dependent yield strength is $\sigma_{y}(\theta)=\sigma_{y_{0}}-c \cdot \Delta \theta$, Eq. (A1) can be presented as

$$
\frac{E \alpha \cdot \Delta \theta}{2}=\sigma_{y_{0}}+\sigma_{y_{0}}-c \cdot \Delta \theta
$$

Then the temperature difference $\Delta \theta$ is obtained by

$$
\Delta \theta=\frac{4 \sigma_{y_{0}}}{2 c+E \alpha}
$$


The dimensionless shakedown limit $\sigma_{t} / \sigma_{y_{0}}$ dominated by alternating plasticity mechanism is determined as

$$
\frac{\sigma_{t}}{\sigma_{y_{0}}}=\frac{2 E \alpha}{2 c+E \alpha}
$$

\section{Appendix B: Ratcheting mechanism}

Let us deduce the shakedown limit dominated by ratcheting mechanism for the Bree problem considering

the yield strength as function of temperature. Referring to the noncyclic method used to solve the classical Bree problem in Reinhardt (2008), we decompose the loading into a constant mechanical load and a cyclic thermal load. Firstly, the cyclic thermal load is applied and produces a linearly distributed bending stress that changes between $\sigma_{r}-\sigma_{t}\left(\right.$ or $\left.-\sigma_{r}\right)$ and $\sigma_{t}\left(\right.$ or $\sigma_{t}-\sigma_{r}$ ) at edges of the plate, as illustrated in Fig. B1. According to the relationship $\overline{m_{1} m_{2}}=\overline{n_{1} n_{2}}$, we can calculate the height $y_{h}$ by

$$
y_{h}=\frac{E \alpha}{(E \alpha-c)} \frac{h}{2}
$$

Next, a limit analysis is performed to determine the maximal allowable constant mechanical load. The plate

fails if applied load exceeds the area of regions below the yield stress distribution, i.e., the shaded area shown in Fig. B1.

Substituting Eq. (B1) into (B2), we can get the dimensionless shakedown limit

$$
h \sigma_{P}=\int_{0}^{y_{h}}\left[\sigma_{y_{0}}-c \cdot \Delta \theta \frac{y}{h}-\left(\sigma_{t}-\sigma_{r}\right)\left(1-\frac{2 y}{h}\right)\right] d y+\int_{y_{h}}^{h}\left[\sigma_{y_{0}}+\sigma_{r}\left(1-\frac{2 y}{h}\right)\right] d y
$$

$$
\frac{\sigma_{P}}{\sigma_{y_{0}}}=1-\left[\frac{E \alpha}{4(E \alpha-c)}\right] \frac{\sigma_{t}}{\sigma_{y_{0}}}
$$

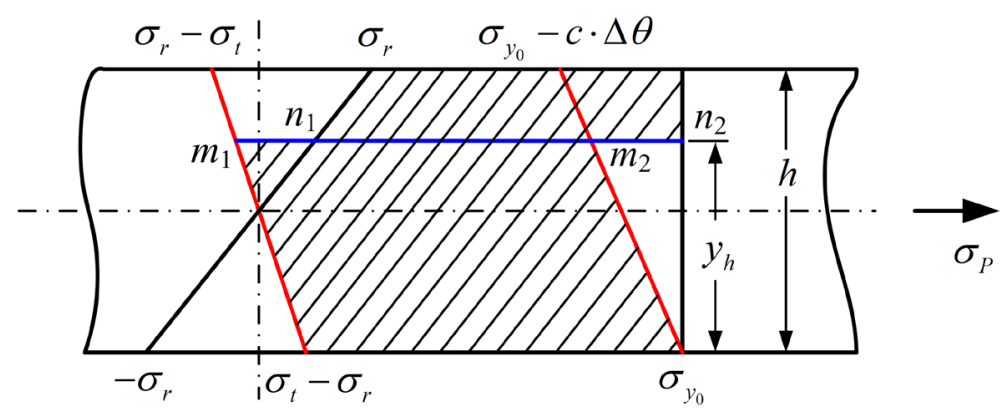

Fig. B1. Stress profile of the plate under reversed thermal bending load and subsequent yield stress distribution. 


\section{References}

Barbera, D., Chen, H., 2015. Creep rupture assessment by a robust creep data interpolation using the Linear Matching Method. Eur J Mech a-Solid 54, 267-279.

Barbera, D., Chen, H., Liu, Y., Xuan, F., 2017. Recent Developments of the Linear Matching Method Framework for Structural Integrity Assessment. Journal of Pressure Vessel Technology 139, 051101-051109.

Borino, G., 2000. Consistent shakedown theorems for materials with temperature dependent yield functions. Int J Solids Struct 37, 3121-3147.

Bradford, R.A.W., Ure, J., Chen, H.F., 2014. The Bree problem with different yield stresses on-load and off-load and application to creep ratcheting. International Journal of Pressure Vessels and Piping 113, 32-39.

Bree, J., 1967. Elastic-plastic behaviour of thin tubes subjected to internal pressure and intermittent high-heat fluxes with application to fast-nuclear-reactor fuel elements. Journal of strain analysis 2, 226-238.

Casciaro, R., Garcea, G., 2002. An iterative method for shakedown analysis. Comput Method Appl M 191, 5761-5792.

Chen, H.F., 2010. Lower and Upper Bound Shakedown Analysis of Structures With Temperature-Dependent Yield Stress. J Press Vess-T Asme 132, 273-281.

Chen, H.F., Ponter, A.R.S., 2001. Shakedown and limit analyses for 3-D structures using the linear matching method. International Journal of Pressure Vessels and Piping 78, 443-451.

Chen, S.S., Liu, Y.H., Li, J., Cen, Z.Z., 2011. Performance of the MLPG method for static shakedown analysis for bounded kinematic hardening structures. Eur J Mech a-Solid 30, 183-194.

Chinh, P.D., 2005. Shakedown static and kinematic theorems for elastic-plastic limited linear kinematic-hardening solids. Eur J Mech a-Solid 24, 35-45.

Cho, N.-K., Chen, H., 2018. Shakedown, ratchet, and limit analyses of $90^{\circ}$ back-to-back pipe bends under cyclic in-plane opening bending and steady internal pressure. European Journal of Mechanics - A/Solids 67, 231-242.

Do, H.V., Nguyen-Xuan, H., 2017. Limit and shakedown isogeometric analysis of structures based on Bézier extraction. European Journal of Mechanics - A/Solids 63, 149-164.

Gokhfeld, D.A., Charniavsky, O.F., 1980. Limit analysis of structures at thermal cycling, Sijthoff \& Noordhoff ed. Alphen aan den Rijn, The Netherlands.

Halphen, B., 2005. Elastic perfectly plastic structures with temperature dependent elastic coefficients. Comptes rendusMécanique 333, 617-621.

Hasbroucq, S., Oueslati, A., de Saxcé, G., 2010. Inelastic responses of a two-bar system with temperature-dependent elastic modulus under cyclic thermomechanical loadings. Int J Solids Struct 47, 1924-1932.

Hasbroucq, S., Oueslati, A., de Saxcé, G., 2012. Analytical study of the asymptotic behavior of a thin plate with temperature-dependent elastic modulus under cyclic thermomechanical loadings. Int J Mech Sci 54, 95-104.

Heitzer, M., 2004. Statical shakedown analysis with temperature-dependent yield condition. Commun Numer Meth En 20, 835-844.

König, J.A., 1987. Shakedown of elastic-plastic structures. Elsevier, Amsterdam.

Koiter, W.T., 1960. General theorems for elastic-plastic solids, in: Sneddon, JN, Hill, R (Eds.), Progress in Solid Mechanics. North-Holland: Amsterdam, pp. 167-221.

König, J.A., 1969. A Shakedown Theorem for Temperature Dependent Elastic Moduli. Bull Acad Pol Sci Tech 17, 161165.

Liu, Y.H., Zhang, X.F., Cen, Z.Z., 2005. Lower bound shakedown analysis by the symmetric Galerkin boundary element method. Int J Plasticity 21, 21-42.

Maier, G., 2001. On some issues in shakedown analysis. J Appl Mech-T Asme 68, 799-807.

Melan, E., 1938. Zur Plastizität des räumlichen Kontinuums. Ingenieur-Archiv 9, 116-126. 
Naghdi, P.M., 1960. Stress-strain relations in plasticity and thermoplasticity. Plasticity Proceedings of the Second Symposium on Naval Structural Mechanics, 121-169.

Nguyen-Xuan, H., Rabczuk, T., Nguyen-Thoi, T., Tran, T.N., Nguyen-Thanh, N., 2012. Computation of limit and shakedown loads using a node-based smoothed finite element method. Int J Numer Meth Eng 90, 287-310.

Peigney, M., 2014. Shakedown of elastic-perfectly plastic materials with temperature-dependent elastic moduli. J Mech Phys Solids 71, 112-131.

Peng, H., Liu, Y., Chen, H., Shen, J., 2018. Shakedown analysis of engineering structures under multiple variable mechanical and thermal loads using the stress compensation method. Int J Mech Sci 140, 361-375.

Polizzotto, C., 2008. Shakedown theorems for elastic-plastic solids in the framework of gradient plasticity. Int J Plasticity 24, 218-241.

Ponter, A.R.S., 2016. Shakedown limit theorems for frictional contact on a linear elastic body. European Journal of Mechanics - A/Solids 60, 17-27.

Ponter, A.R.S., Carter, K.F., 1997a. Limit state solutions, based upon linear elastic solutions with a spatially varying elastic modulus. Comput Method Appl M 140, 237-258.

Ponter, A.R.S., Carter, K.F., 1997b. Shakedown state simulation techniques based on linear elastic solutions. Comput Method Appl M 140, 259-279.

Ponter, A.R.S., Chen, H.F., 2001. A minimum theorem for cyclic load in excess of shakedown, with application to the evaluation of a ratchet limit. Eur J Mech a-Solid 20, 539-553.

Ponter, A.R.S., Engelhardt, M., 2000. Shakedown limits for a general yield condition: implementation and application for a Von Mises yield condition. Eur J Mech a-Solid 19, 423-445.

Prager, W., 1956. Shakedown in elastic, plastic media subjected to cycles of load and temperature. Division of Applied Mathematics, Brown University.

Reinhardt, W., 2008. A Noncyclic Method for Plastic Shakedown Analysis. Journal of Pressure Vessel Technology 130, 0312091-0312096.

Simon, J.W., Weichert, D., 2011. Numerical lower bound shakedown analysis of engineering structures. Comput Method Appl M 200, 2828-2839.

Spiliopoulos, K.V., Panagiotou, K.D., 2014. A Residual Stress Decomposition based Method for the Shakedown analysis of structures. Comput Method Appl M 276, 410-430.

Staat, M., Heitzer, M., 2003. Numerical methods for limit and shakedown analysis deterministic and probabilistic problems. NIC-Directors, pp. 1-306.

Stein, E., Zhang, G., Huang, Y., 1993. Modeling and computation of shakedown problems for nonlinear hardening materials. Comput Method Appl M 103, 247-272.

Vu, D.K., Staat, M., 2007. Shakedown analysis of structures made of materials with temperature-dependent yield stress. Int J Solids Struct 44, 4524-4540.

Weichert, D., Ponter, A., 2014. A historical view on shakedown theory, in: Stein, E. (Ed.), The History of Theoretical, Material and Computational Mechanics-Mathematics Meets Mechanics and Engineering. Springer, pp. 169-193.

Yan, A.M., Hung, N.D., 2001. Kinematical shakedown analysis with temperature-dependent yield stress. Int J Numer Meth Eng 50, 1145-1168.

Zarka, J., 1980. Direct analysis of elastic-plastic structures with 'overlay' materials during cyclic loading. Int J Numer Meth Eng 15, 225-235.

Zouain, N., Borges, L., Silveira, J.L., 2002. An algorithm for shakedown analysis with nonlinear yield functions. Comput Method Appl M 191, 2463-2481. 